\title{
Vestas V90-3MW Wind Turbine Gearbox Health Assessment Using a Vibration-Based Condition Monitoring System
}

\author{
A. Romero, ${ }^{1,2}$ Y. Lage, ${ }^{1}$ S. Soua, ${ }^{1}$ B. Wang, ${ }^{2}$ and T.-H. Gan ${ }^{1,2}$ \\ ${ }^{1}$ Condition and Structural Health Monitoring, TWI Ltd, Cambridge CB21 6AL, UK \\ ${ }^{2}$ School of Engineering and Design, Brunel University, Uxbridge UB8 3PH, UK \\ Correspondence should be addressed to A. Romero; antonio.romero@affiliate.twi.co.uk
}

Received 15 March 2016; Revised 20 June 2016; Accepted 11 July 2016

Academic Editor: Lu Chen

Copyright (C) 2016 A. Romero et al. This is an open access article distributed under the Creative Commons Attribution License, which permits unrestricted use, distribution, and reproduction in any medium, provided the original work is properly cited.

\begin{abstract}
Reliable monitoring for the early fault diagnosis of gearbox faults is of great concern for the wind industry. This paper presents a novel approach for health condition monitoring $(\mathrm{CM})$ and fault diagnosis in wind turbine gearboxes using vibration analysis. This methodology is based on a machine learning algorithm that generates a baseline for the identification of deviations from the normal operation conditions of the turbine and the intrinsic characteristic-scale decomposition (ICD) method for fault type recognition. Outliers picked up during the baseline stage are decomposed by the ICD method to obtain the product components which reveal the fault information. The new methodology proposed for gear and bearing defect identification was validated by laboratory and field trials, comparing well with the methods reviewed in the literature.
\end{abstract}

\section{Introduction}

Despite the current global economic situation the wind turbine industry is still growing worldwide [1]. However, the wind turbine industry experiences premature turbine component failures, which leads to increase in the operation and maintenance $(\mathrm{O} \& \mathrm{M})$ costs and loss of productivity due to turbine downtime $[2,3]$. The O\&M costs constitute a sizeable share of the total annual costs of a wind turbine. For a new turbine, O\&M costs may easily make up $20 \%-25 \%$ of the total levelised cost per kWh produced over the lifetime of the turbine [4]. Unpredictable failure of certain wind turbine components, such as turbine blades, tower, gearbox, generator, braking system, and yaw system, can lead to substantially higher maintenance costs and reduced availability of wind turbines. As a result, O\&M costs are attracting greater attention, as there is a need for the industry to reduce the turbine downtime, increase reliability, and decrease the cost of the energy (COE).

Wind turbine gearboxes tend to fail more prematurely than those in any other applications. Gearboxes do not always achieve their desired 20-year design life, failing prematurely from 2 to 11 years. Although it is well documented in literature that the failure rate of mechanical components is lower in comparison with the electrical subsystems, mechanical failures still create unplanned maintenance, long turbine downtimes due to gearbox replacement, and rebuild which increases the warranty reserves. Based on the data compiled in the Wind Stats Newsletter which covers from 2003 to 2009, gearboxes are the subsystem that causes the highest downtimes (Figure 1) [5, 6]. Wind industry is experiencing higher gearbox failure rates than other due to underestimation of true operating loads, unexpected overloads due to unusual operating conditions, defective design of gearbox components, and poor maintenance, all of which have clear effects on gearbox reliability. From the O\&M point of view, the main concerns are the following: high replacement costs after failure, high costs of the removal and reinstallation works because a crane is needed, and high revenue losses due to the long downtime [7]. All the previous factors trigger an increase in the cost of the energy as previously stated. In order to decrease this cost, turbine uptime has to be increased, a goal which can be reached by improving gearboxes reliability [8-13]. For this reason, the Vestas V90 gearbox is the main targeted subsystem of this paper. 


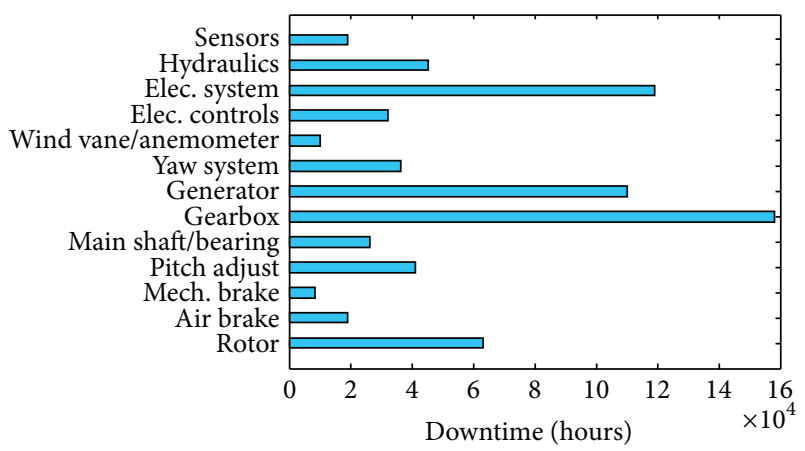

FIGURE 1: Wind Stats: 2003-2009 aggregated downtime per turbine subsystem.

Vibration-based monitoring of all drive train components is the most developed and widely applied condition monitoring technique by far [14-17]. A survey carried out by the UK Supergen Wind Energy Technologies Consortium [18] shows that 14 out of 20 commercially available wind turbine condition monitoring system (CMS) provide gearbox vibration monitoring. Another survey carried out by Durham University [19] shows that 27 out of 36 widely available CMS are based on drivetrain vibration analysis. Oil-based analysis CMS are also used for gearbox monitoring purposes. This technology is in an early development stage as regards sensor technology and the validation of its capabilities for fault detection [20]. Acoustic Emission is becoming a typical drivetrain $\mathrm{CM}$ practice. A recent study on wind turbine CM shows a design of a new continuous condition monitoring system with automated warnings based on a combination of vibration and $\mathrm{AE}$ analysis [21,22]. AE can detect faults earlier than vibration $[23,24]$ but implementation is more complicated due to equipment noise which reduces the quality of the output signals [25]. SCADA systems are also used for condition monitoring of wind turbines although they are not a standalone solution. They store 10 minute-average data which is valuable to help other CMS achieve better fault detection performances [7].

The technique applied in this paper is vibration analysis using accelerometers mounted in specific locations on the machine. The reason vibration analysis is used instead of one of the aforementioned methods is the advantages this technique offers. In comparison to oil analysis, vibration analysis can detect failures inside and outside the gearbox and can be used for online monitoring without incurring high costs [16]. Additionally, small defects generate intense vibration signatures which are detectable by the accelerometer. However they do not necessarily cause changes in the chemical composition [26].

The majority of existing commercially available vibrationbased CMS use time domain, frequency domain, or timefrequency analysis methods. Vibrations in the time domain have been widely studied. Statistical and parameter-based methods have shown to be useful indictors of the system condition [27]. Minimum and maximum value, peak to peak value, root mean square (RMS), kurtosis, skewness, crest factor are all examples of time domain features. Comparisons between the pristine status and the current have been carried out using trend analysis [28]. Features reflect component deterioration only when working under changeless operating conditions. Time synchronous averaging (TSA) and planet separation methods resample the vibration data synchronously with the shaft rotation for the sake of extracting periodic waveform from noisy data [29]. Amplitude demodulation has proven to be appropriate for detecting defects that produce impacting [9]. Most of the commercially available vibration-based CMS focus on the frequency domain analysis based on Fast Fourier Transform (FFT) [30-32], order analysis, cepstrum analysis [33], envelope analysis, and so forth, which demonstrated to be effective at detecting gear faults. FFT is suitable for analysing steady-state or quasi-steady vibrations with slowly varying frequencies $[34,35]$. Therefore FFT is not appropriate for wind turbine monitoring due to their stochastic operation behavior (variable aerodynamic loads and extreme environmental conditions which make the running speed change continuously). Vibrations coming from the wind turbine's gear or bearing are considered as nonstationary and nonlinear. To deal with nonstationary and nonlinear signals, time-frequency methods such as the ShortTime Fourier Transform (STFT) [36], Wigner-Ville distribution (WVD) [37], or wavelet transform (WT) are required $[38,39]$. Wavelet analysis is probably the most popular technique. Continuous wavelet transform, discrete wavelet transform, and harmonic wavelet transform have been validated as methods for wind turbine condition monitoring [40-43]. Wavelet transform methods have the drawback that the basic functions of the decompositions are fixed and do not necessarily match the varying nature of the signals [44]. Signal decomposition methods have been applied to the practical gear and rolling bearing fault diagnosis. Empirical Mode Decomposition (EMD) has been presented as a more advanced condition monitoring technique to ensure the high availability of wind turbines [45]. The main downsides of EMD include the use of cubic spline to interpolate the local extrema of the signal which experiences end effect, mode mixing, overshoot, and undershoot problems [46, 47]. Local Mean Decomposition (LMD) is an improved version of EMD which also suffers from mode mixing, distorted components, and time consuming decomposition. LMD can be more effective than EMD in capturing local features of the nonlinear and nonstationary signals [48]. The Intrinsic Time-scale Decomposition (ITD) method overcomes the limitations of EMD listed earlier, as well as those previously mentioned, and is associated with more classical approaches such as Fourier and wavelets [49]. ITD decompose the nonstationary signal into a sum of proper rotation components (PRs) which are not real monocomponents. This causes erroneous instantaneous characteristics.

The existing work has some limitations. Most of the existing methods applied for fault detection in rotating machinery are signal processing based and they consist of finding the faulty peak in the frequency spectrum. Fault detection is carried out by comparison of the pristine and faulty frequency spectrum which is sensitive to noise methodology [30]. The task of identifying faulty peaks has to be done offline which falls into higher costs of labour and computational 
complexity. In addition, offline analysis of the data gathered does not provide any benefit as faults are identified after they occurred. As is well known, practical vibrations are nonlinear and nonstationary due to the complexity of rotating machinery systems [48]. Fast Fourier Transform (FFT) did not show good result when it was applied to that type of complex vibrations. Nonadaptive time-frequency methods do not provide with a meaningful interpretation either [5052]. Consequently, a novel methodology for automated fault diagnosis in rotating machinery is needed to avoid loss of time in planning and carrying out unnecessary operation and maintenance (O\&M) tasks, reduce machinery downtime, increase reliability, and reduce the cost of energy (COE).

The algorithms and methodology presented in this paper highlight some of the limitations of vibration analysis when it is applied for fault diagnosis. The approach uses a combination of time and time-frequency adaptive techniques to develop an automated solution for condition monitoring of wind turbines which contributes to the state of the art. Automation is a must in industrial applications such as wind turbine monitoring to reduce the manual inspection of data. These algorithms are based on unsupervised learning that uses statistical process control (SPC) charts for defining the healthy status of the machinery. Signals considered as faulty are processed using the intrinsic characteristic-scale decomposition (ICD) method. ICD is a relatively novel adaptive method which has been first proposed by Li et al. [53]. With ICD, any nonlinear and nonstationary signal can be decomposed into a collection of product components (PCs). The envelope spectrum of these PCs can identify the faulty frequencies in a gearbox. This proposed methodology is explained in this paper.

\section{Novel Software Concept for Fault Detection in Wind Turbines}

The application of vibration analysis is well developed in the field of rotating machinery. In spite of the fact that industrial machinery is monitored using vibration analysis, the industry still experiences premature failures. Failure in machinery implies an increase of the downtime and subsequently an increase of the cost of the energy (COE). The current systems used to have full remote control of the individual wind turbines or even an entire wind farm health are SCADA (Supervisory Control And Data Acquisition) which offer full remote control and supervision of individual wind turbines. SCADA systems give an overview of all the relevant features to monitor any health changes of wind turbines such as temperature, pitch angle, electrical parameters, and rotor speed. These data gathering systems provide real time and historical information. The real time and historical data are compared to assess whether or not there is a failure arising or happening.

A new methodology which combines operating and vibration data for condition monitoring of wind turbines in rotating machinery is showcased in this paper. The aim is to propose a novel solution that helps the wind industry improve the reliability and availability of wind turbines. The objectives to reach with the development and implementation of this novel methodology are as follows:

(i) Establishment of a baseline representative of the healthy status of the wind turbine.

(ii) Setting of operational limits of the machine being studied.

(iii) Identification of deviations (outliers) from the baseline which could be indicative of machinery failure or malfunctions which are being developed within it.

(iv) Application of a time-frequency domain technique for discarding any false alarm and identifying the source of defect if any.

(v) Database creation for condition monitoring management purposes.

The algorithm developed to reach the aforementioned objectives can be split into the following four modules: baseline generation, forcing frequencies calculation, intrinsic-scale decomposition (ICD), and data base.

Figure 2 depicts the flow chart novel methodology for condition monitoring of wind turbines gearboxes proposed in this paper. The algorithm is recognized as two lines which work in parallel, coming together in a single endpoint. The proposed method starts gathering vibration data and takes 10-minute averages of the speed of the low speed shaft (LSS) and power output continuously. Then, vibrational data passes through a signal conditioning stage and the rotor speed is used for calculating the forcing frequencies of the machine being studied. It is important to know the speed of the LSS as some wind turbines and other pieces of rotating machinery work at different speeds. Thus, the method selected for storing the data gathered is based on bins which are related to the speed of the LSS at the time the measurement is taken. The number of bins is selected by the operator whereas the bin width is established according to the maximum speed of the machine and the number of bins previously mentioned.

Research in the laboratory was carried out to select the feature that depicts better and more reliable changes in the operational status of gearboxes. Counts parameter, root mean square (RMS), peak value, and crest factor were studied. Peak value showed an increase with the onset of defect in gearboxes but sometimes that feature was badly affected by single noise spikes. For that reason, peak value and crest factor were considered not reliable indicators of defect. Counts parameter was not considered reliable either as it has a strong dependence on the threshold value selected for its calculation. RMS levels increased with the increase of defect within the gearbox studied and results were not affected by single noise spikes as much as the peak value. Therefore, RMS was selected as the feature to be binned. Depending on the application, different features might contain more relevant information for processing with monitoring systems [54]. Then the method depicted in Figure 2 is able to generate a baseline representative of the normal operation conditions of a wind turbine gearbox and use that baseline to assess the current health of the gearbox. At this stage, deviations from the baseline may or may not be an indication of defect. Accordingly, a novel timefrequency domain technique is applied to the data which 


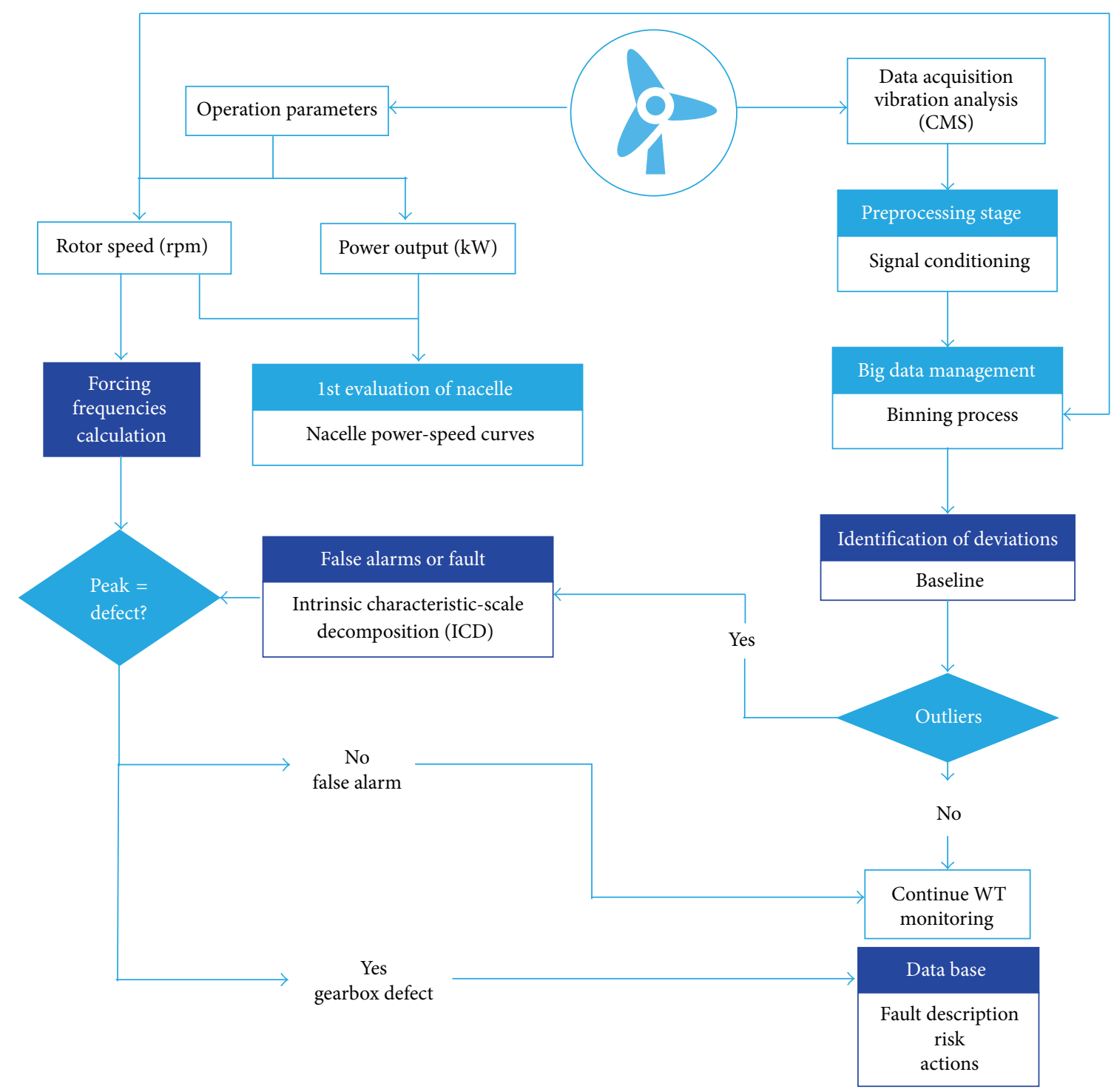

FIGURE 2: Flow chart of a novel condition monitoring algorithm for gearbox fault detection.

is causing deviations, that is, to the outliers. The technique, which is called intrinsic characteristic-scale decomposition (Figure 4), demodulates the signals until the faulty frequency is easy to identify. The output of the ICD is compared with the forcing frequencies previously calculated to conclude whether or not there is a defect. If there is a match between the ICD and the frequencies calculated, the source of defect is identified and the information is recorded in a database to evaluate the risk and the actions which need to be taken. On the other hand, if there is no match, the outlier is considered as a false alarm and the monitoring process continues.

The main parts within the algorithm described in Figure 2, the baseline generation and the demodulation technique (ICD), are explained extensively in this section.

2.1. Identification of Deviations from Normal Operation Conditions Based on a Baseline. The baseline is a statistical process control that can be used when a large number of similar files are being produced, such as data coming from the wind turbine. Wind turbine monitoring is subject to variability. The variability present when a process is running well is called short term or inherent variability and is usually measured by the standard deviation. The vibration signatures files generated will have a target value. When defects appear, this value increases or decreases depending on the feature selected for the baseline generation. This method falls within the machine learning field of research. It is classified as an unsupervised parametric learning method [55] because the source of defect is unknown and it is based on the statistical representation of vibration features. It acts as a unary classification; that is, it establishes discrimination criteria by learning from a training set in order to identify whether the data belongs to pristine condition of the method or to a novel class.

The purpose of generating a baseline with the wind turbine data is to produce an alarm when the process values have moved away from the target. A second purpose is to generate 


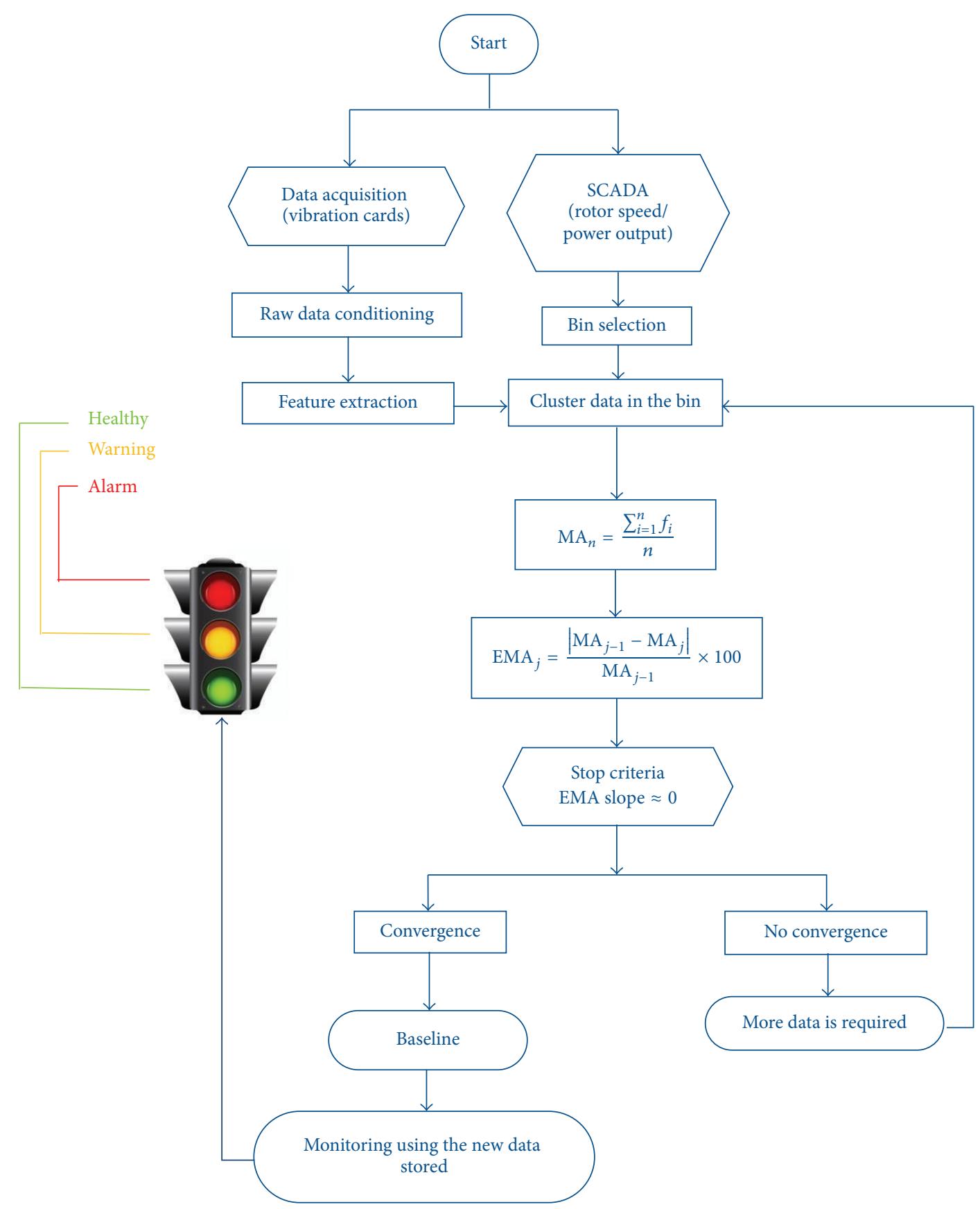

FIGURE 3: Flow chart for the baseline generation algorithm.

a signal when item to item variability has increased. In either case appropriate action must be taken by a machine operator or an engineer. Statistics can only give the signal; the on action relies on other skills. Setting the alarm limits based on statistics enables all alarm levels on a complex machine, such as wind turbine with many transducers, to be calculated in seconds instead of taking many hours to view the data and set the levels manually. Thus, the monitoring process can be carried out more economically. Automation of the alarm setting process can greatly improve the efficiency of the monitoring process. Figure 3 shows a more detailed flow chart of the baseline generation method. After having binned the features extracted in the suitable bin according to the rotor speed, the method needs to establish when the data available is enough to determine the normal operation limits of the wind turbine gearbox. Obviously, the more data the better to establish reliable alarm limits. However, it entails spending more time learning from the machine which is not the best practice when early fault detection is a goal. Therefore, a compromise between reliability and time efficiency is needed. A convergence criterion to ensure that the normal operation limits are calculated using the minimum number of files is 


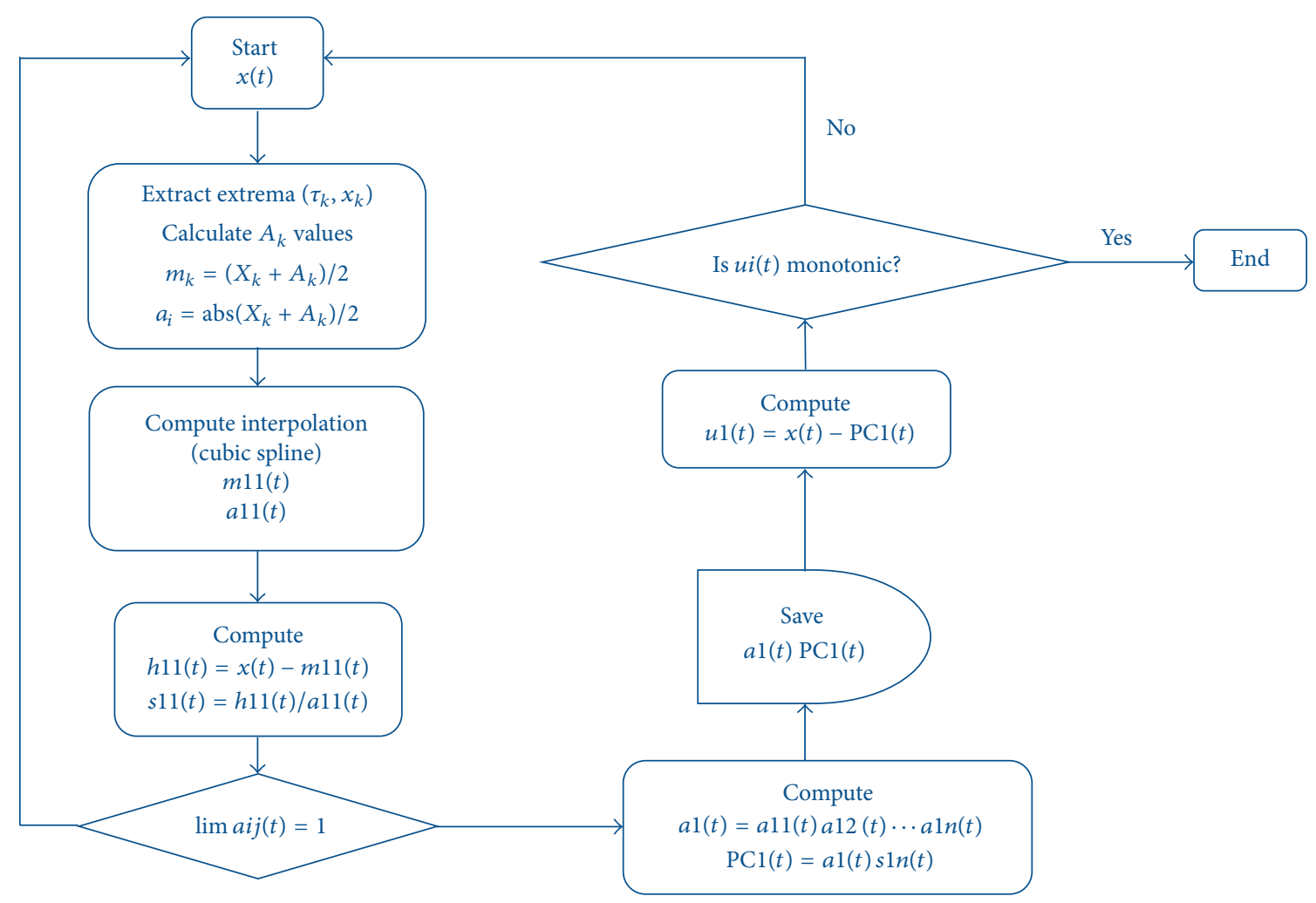

FIGURE 4: Flow chart of the ICD method.

presented in this paper. In this way, the wind turbine gearbox health can start to be assessed as soon as possible. Due to different variability of the data in different bins, the number of files required will vary for each bin. Therefore, convergence is studied separately in every single bin.

The process starts calculating the moving average (MA) of the data stored in the bin being studied. MA is a trustworthy parameter which indicates when the addition of more data will not have any effect on the calculation of the alarm limits. The moving average error (EMA) between consecutive files is calculated and it establishes the termination conditions. Considering the coordinates of the last EMA value calculated $\left(x_{n}, y_{n}\right)$ and another one calculated earlier $\left(x_{n-m+1}, y_{n-m+1}\right)$, where $m$ indicates the number of EMA points included between the last two, the slope of the straight-line connecting both can be figured. The slope is not calculated using the last two measurements as that would be more a short term convergence indicator rather than a medium or long term convergence indicator. Slope can be calculated using

$$
\gamma=a \tan \left(\frac{y_{n}-y_{n-m+1}}{x_{n}-x_{n-m+1}}\right) .
$$

The stopping criterion is satisfied when $\gamma \approx 0^{\circ}$ which means that the straight-line between two measurements properly spaced in time is nearly horizontal. In that case, it can be ensured that the variability of the EMA when new data is added to that specific bin is that low that the normal operation limits can be established reliably. Limits allow determining whether or not the process is under control. The purpose is to provide a representative vibration level across a range of rotor speeds, for improving the reliability of wind turbine gearboxes and thereby help define appropriate vibration limits. If the limits are too far from the target value, small deviations from the target value may go undetected, but if the limits are too close to the target value there will be a large number of false alarms (meaning there will be a signal for action when the process mean is on target and no action is necessary). The baseline is generated using the mean $(\mu)$ of the values required according to the stopping criterion previously explained and their standard deviation $(\sigma)$. Two kinds of limits are established: warning limits and action limits. Before constructing the control chart, the probability level $(\alpha)$ value for the warning and alarm limits has to be selected. According to the literature related to statistical process control (SPC) charts $[56,57]$, it has been convenient to set the warning limits so that, if the mean is on target, $95 \%$ of sample means lie within them. Limits are calculated as the mean plus/minus $p$ times the standard deviation of the data stored in a specific bin. The action limits are set so that $99.8 \%$ of samples lie within them when the mean is on target. Given the value of $\alpha$, the number of standard deviations $(p)$ used for the calculation of the upper control limits (UCL) and lower control limits (LCL) is extracted from the $t$ distribution table, using an input value equal to $1-\alpha / 2$. Therefore, for the warning limits, $p$ is 1.96 which means that only $5 \%$ of the values should be outside the limits if the features under study are in the same condition as when the signature was calculated. For 
the action limits, $p$ is 3.09. The warning and action limits are defined as follows:

$$
\begin{aligned}
\text { Warning Limits } & =\mu \pm 1.96 \sigma, \\
\text { Alarm Limits } & =\mu \pm 3.09 \sigma .
\end{aligned}
$$

The standard deviation will be an estimation of the true value and $95 \%$ and $99.8 \%$ are figures which have been selected according to the literature. For these reasons and for simplicity the limits are often set at

$$
\begin{aligned}
\text { Warning Limits } & =\mu \pm 2 \sigma, \\
\text { Alarm Limits } & =\mu \pm 3 \sigma .
\end{aligned}
$$

In this specific case, the target value is not known and it will depend on the gearbox which is being monitored. When this happens, the data clustered within each bin is taken and the sample mean is used as a target value. One should clarify that this is accomplish just when the process is running satisfactory.

Finally, the new data gathered is plotted in front of the limits previously determined to evaluate the health of the gearbox. New RMS values falling out of the limits are a clear indication of a process out of target. Nevertheless, it does not necessarily mean that is due to a malfunction or defect within the turbine. The classification process to distinguish between faults and false alarms is carried out by the module described in the following section. Three areas can be distinguished in the baseline plot: Zone A is define as the area where the turbine operates free of fault; Zone B is the area between the warning and alarm limits and where minor faults will appear; and Zone $\mathrm{C}$ is the area above the alarm limit and where acute fault to danger will be localized.

On the other hand, if the termination criterion is not satisfied in a bin, more data is required and the whole process needs to continue.

\subsection{Gearbox Fault Diagnosis for Wind Turbines Based on ICD} Frequency Spectrum. The time series of abnormal events are subjected to a time-frequency signal processing technique which is suitable for nonlinear and nonstationary vibrations such as faulty gearbox signals. In a defective gear or rolling element the resonance frequency is excited and it is modulated by the transient impulse with defective frequency. The intrinsic characteristic-scale decomposition method (ICD) decomposes the nonstationary signal into a series of product components (PCs) so it is possible to diagnose gearbox and rolling elements defects. This method is needed in order to demodulate the feature and extract the fault frequency by carrying out envelope spectrum analysis of the first few PCs. Therefore, the output of this module will be the frequency spectrum of the first enveloped PCs which can identify the faulty frequencies in gearbox and rolling elements successfully. This method has been effectively applied by Li et al. [53] for faulty frequencies identification. The results demonstrate that ICD can get accurate monocomponents when the method is applied to broken tooth detection in gears or inner race defects detection in bearings.
TABLE 1: Specifications of the test's rig gearbox.

\begin{tabular}{lc}
\hline Ratio & $1.5: 1$ \\
Pinion teeth & 18 \\
Gear teeth & 27 \\
\hline Forcing frequencies & Orders \\
\hline Input frequency $\left(f_{\text {in }}\right)$ & $1 \mathrm{x}$ \\
Output frequency $\left(f_{\text {out }}\right)$ & $0.67 \mathrm{x}$ \\
Gear mesh frequency $(\mathrm{GMF})$ & $18 \mathrm{x}$ \\
\hline
\end{tabular}

Once the spectrum of the enveloped PCs is obtained, the remaining peaks in the FFT are compared with the forcing frequencies of the gearbox. If any of the frequency calculated correlates to any peak in the envelope spectrum coming from the ICD method, the false alarm hypothesis would be discarded and the source of defect would be identified. On the contrary, if there is a lack of correlation between the theoretical values and the envelope spectrum, the outlier being analysed is considered as a false alarm.

\section{Laboratory Trials on a Test Rig}

Experiments were conducted at laboratory scale to validate the methodology above explained. In this section, the layout and results obtained after applying the algorithm described in Figure 2 are presented.

3.1. Laboratory Experiments Set-Up. To verify the effectiveness of the proposed methodology, a couple of case studies were conducted at laboratory scale at the Machinery Fault Simulator from Spectraquest Inc. The aim was to recreate the stochastic behaviour of wind turbines by gathering data at different speeds so the results of this experiment can be useful for showcasing the applicability of the method to field trials in a wind turbine gearbox.

The test rig, utilized for the purpose of dataset collection, is shown in Figure 5(a). It consists of a $0.75 \mathrm{~kW}$ variable frequency drive (VFD) which controls the motor shown in Figure 5(a). In the first experiment, the motor is connected over the universal joint shaft to the single stage gearbox with spiral bevel gears. One of the two gears is shown in Figure 5(b). Figure 6 depicts a diagram of the gearbox. The specifications of the gearbox are shown in Table 1. Vibrations generated by this subsystem are measured in the radial direction, using a CTC AC150-1 accelerometer mounted vertically on the case. It is an industrial type IEPE accelerometer whose sensitivity is $100 \mathrm{mV} / \mathrm{g}$ and its frequency range goes from $1 \mathrm{~Hz}$ until $10 \mathrm{kHz}$. Input shaft speed is measured with a noncontacting proximity probe.

Two gearboxes were tested. The first gearbox was free of faults whereas the second one was in faulty conditions. Figure 5(b) shows the faulty gear from the second gearbox which is missing a tooth. Tests were performed in both gearboxes at variable speeds between $25 \mathrm{~Hz}$ and $45 \mathrm{~Hz}$ using a $5 \mathrm{~Hz}$ step.

For the second experiment, the motor is connected to a $91.4 \mathrm{~cm}$ shaft supported by one Rexnord ER12K ball bearing which is mounted on a stand as shown in Figure 7. Damage 


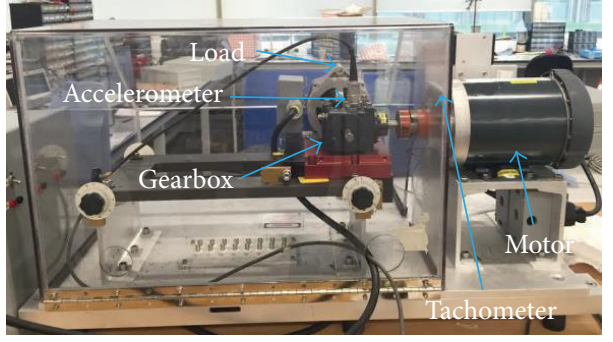

(a)

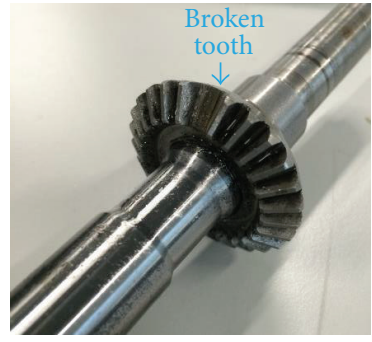

(b)

FIGURE 5: Layout of the test rig: (a) sensor attachment and (b) the faulty gear with a broken tooth.

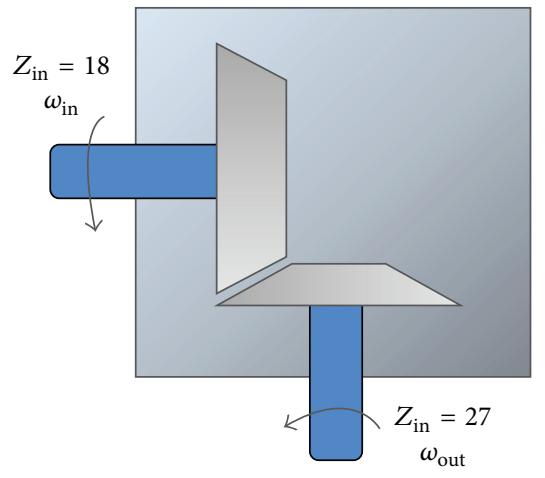

Figure 6: Diagram of the test rig's gearbox.

is introduced by replacing a healthy bearing by a predamaged specimen. The damage cases include ball spalling, inner race, and outer race. Li et al. [53] applied the ICD method to a bearing with inner race defect. In order to make a contribution to the current knowledge a bearing with an outer race defect was utilized for the experiments. In this way, the ICD method can be validated for another type of roller bearing fault. The forcing frequency (BPFO) can be calculated introducing the parameters defined in Table 2 into the following equation:

$$
\mathrm{BPFO}=\left(\frac{N_{b}}{2}\right)\left(1-\frac{N_{b}}{d_{p}} \cos (\alpha)\right) .
$$

The value of the abovementioned forcing frequency expressed in orders is $3.044 x$, where $x$ is the rotating frequency at the gearbox input.

3.2. Results Analysis. The results from the laboratory experiments performed in a test rig gearbox are presented in Figure 8. First of all, healthy data was gathered to establish the normal operation condition limits. The system decides autonomously when the data gathered is enough for establishing these limits based on the convergence criteria previously described.

Convergence plots for each bin are shown in Figure 8. These plots reveal the effect of adding a new measurement to the current data. The convergence criteria marks with a light blue dotted line when the learning process is finished in each
TABLE 2: Specifications of the test's rig bearings.

\begin{tabular}{lc}
\hline \multicolumn{2}{c}{ MB ER12K bearing Rexnord } \\
\hline Outer diameter $D(\mathrm{~mm})$ & 47 \\
Inner diameter $d(\mathrm{~mm})$ & 19 \\
Pitch diameter $d_{p}(\mathrm{~mm})$ & 33.5 \\
Ball diameter $d_{B}(\mathrm{~mm})$ & 7.9 \\
Outer ring width $B(\mathrm{~mm})$ & 15.8 \\
Number of ball $N_{b}$ & 8 \\
Contact angle $\alpha\left({ }^{\circ}\right)$ & 0 \\
\hline
\end{tabular}

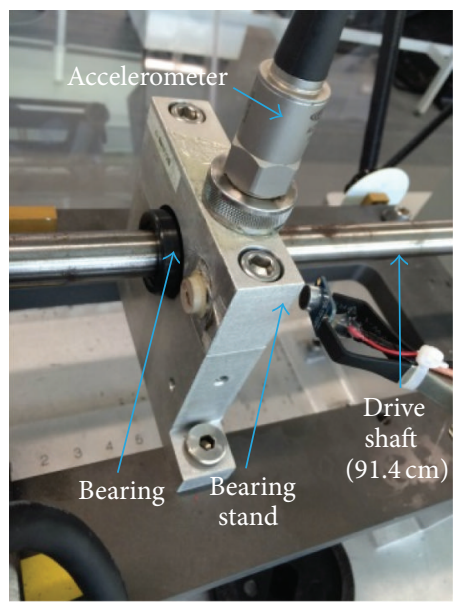

FIGURE 7: Experimental set-up with a faulty bearing.

bin, which does not generally happen simultaneously in all the bins. The number of files needed to determine the baseline limits reliably is depicted in Table 3 . Following on, warning and alarm limits are calculated and plotted as dark and light blue lines, respectively (Figure 9).

A new set of 50 measurements was gathered for each bin when the gearbox was working in pristine conditions. This new set of data validates the capabilities of the normal operation limits calculated. The RMS values extracted from the vibration signals are plotted as dark blue points in Figure 9. Since the data was acquired in healthy conditions, features should fall within the limits, revealing that the gearbox status has not changed. The effectiveness of the baseline is evaluated by calculating the percentage of data that is within 

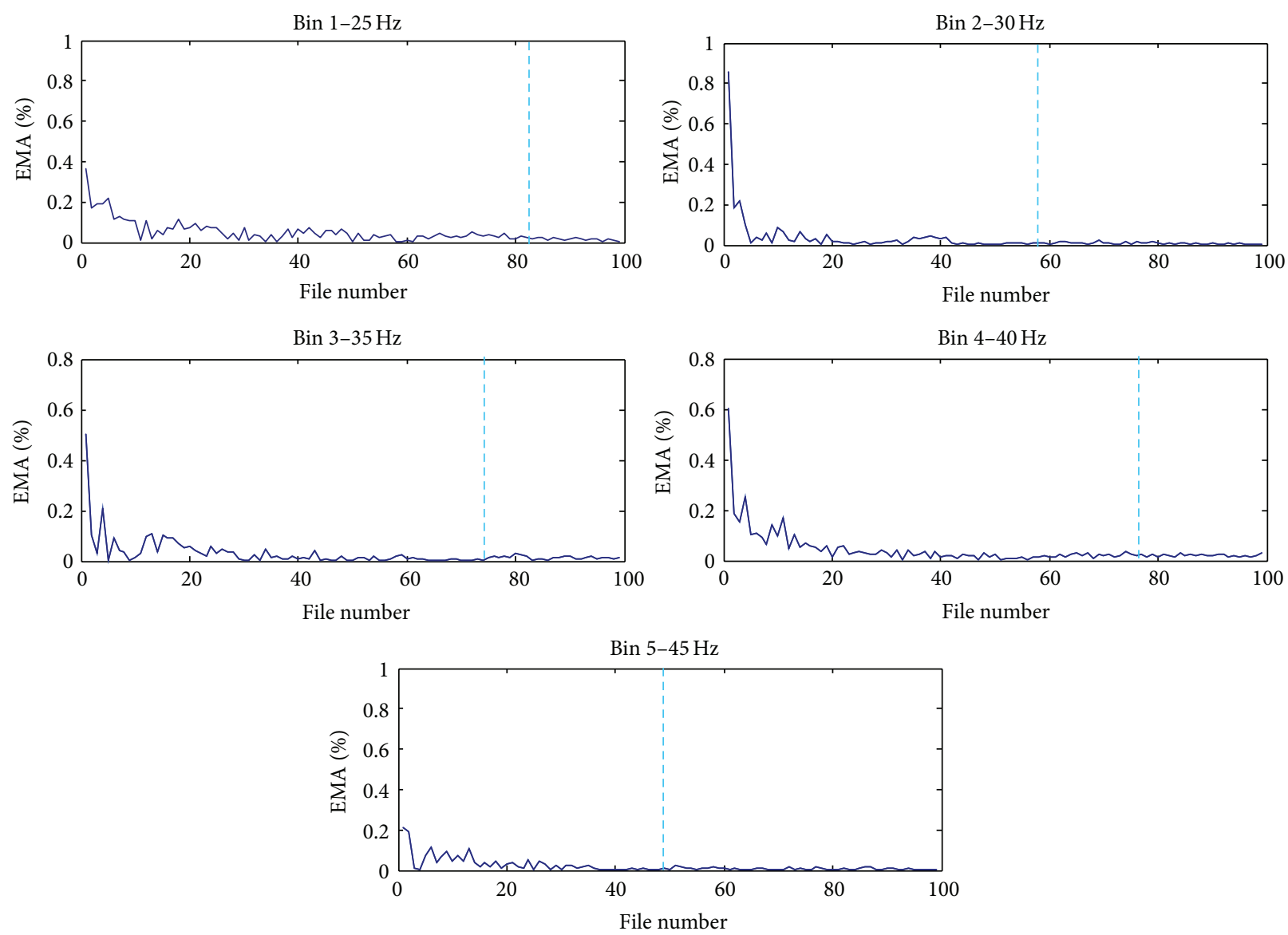

FiguRE 8: Vibration data convergence.

TABLE 3: Number of files for the baseline generation and effectiveness probed with an additional set of data.

\begin{tabular}{lccccc}
\hline & Bin 1 & Bin 2 & Bin 3 & Bin 4 & Bin 5 \\
\hline $\begin{array}{l}\text { Rotation } \\
\text { speed (Hz) }\end{array}$ & 25 & 30 & 35 & 40 & 45 \\
$\begin{array}{l}\text { Number of } \\
\text { files }\end{array}$ & 84 & 58 & 72 & 77 & 48 \\
$\begin{array}{l}\text { Number of } \\
\text { outliers }\end{array}$ & 0 & 0 & 2 & 1 & 2 \\
$\begin{array}{l}\text { Data within } \\
\text { the limits (\%) }\end{array}$ & 100 & 100 & 96 & 98 & 96 \\
\hline
\end{tabular}

the limits. There are 2 outliers out of 50 in bins 3 and 5 whereas there is just one in bin 4 . The algorithm assesses the gearbox as healthy for bins 1 and 2 in all cases. The outliers are located between the alarm and the warning limits. Therefore, the quality of the current results has to be assessed according to the $95 \%$ probability factor defined in the previous section of this paper. It can be concluded that the results are promising as the percentage of data lying within the limits is higher than $95 \%$.

The healthy gearbox was replaced by the one with a broken tooth and new sets of 50 measurements were taken for each bin. The extracted RMS values are plotted as light blue

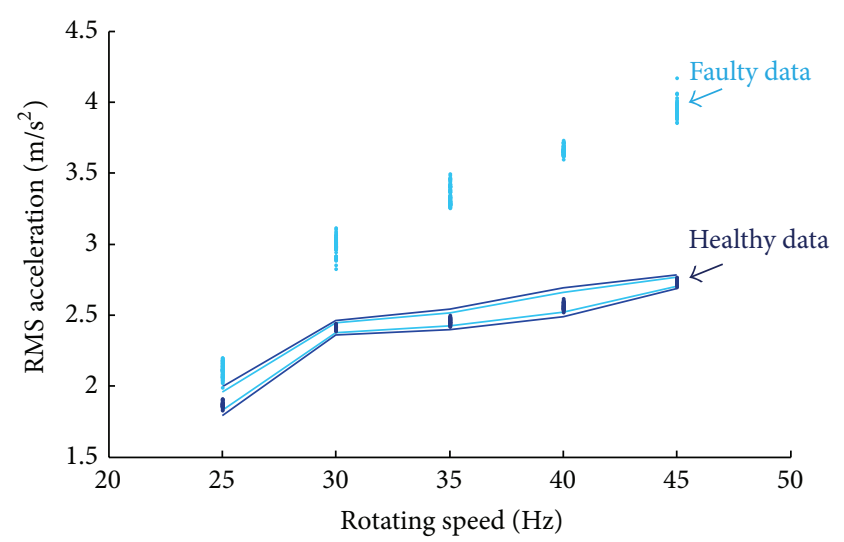

FIGURE 9: Baseline of the test rig operating at variable speed using the RMS value of the acceleration.

points in Figure 9. As can be seen, the new values are deviated from the targeted mean. The deviation in bin 1 is not big and it can even be seen that one of the points falls between the upper alarm and warning limits. However, for higher speeds all the points are outliers. In addition, positive correlation between the deviation from the targeted mean and the rotation speed has been noted. In conclusion, the baseline algorithm is experimentally demonstrated to be able 


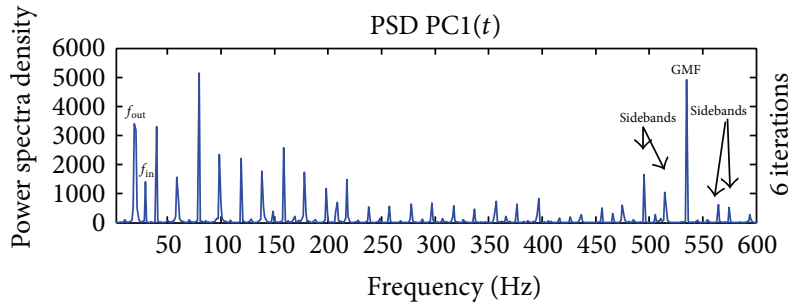

(a)

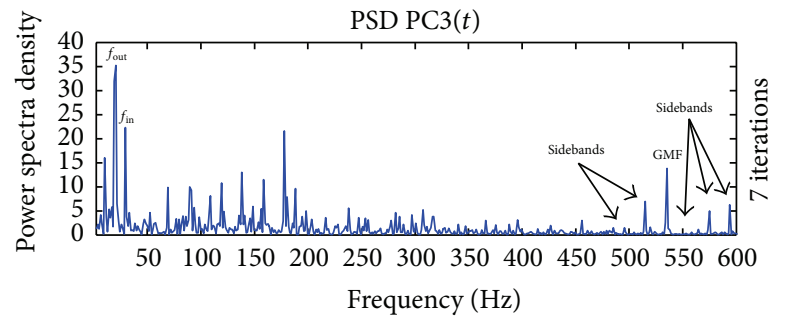

(c)

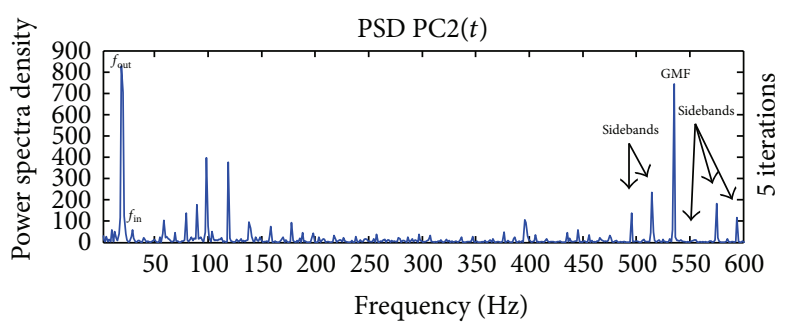

(b)

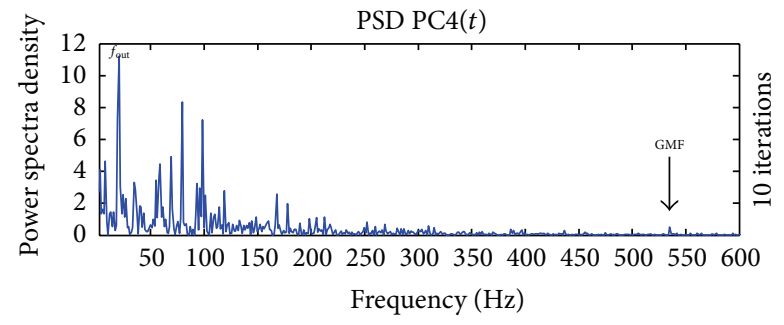

(d)

FIGURE 10: Envelope spectra of the obtained components from ICD (gearbox): (a) PC1(t), (b) PC2, (c) PC3(t), and (d) PC4(t).

to distinguish between the healthy and the faulty condition of a gearbox successfully.

To verify the effectiveness of the ICD method revealing the source of defect, the algorithm is applied to one of the outliers falling in bin 2. That file was gathered when the variable frequency drive was running at $30 \mathrm{~Hz}$ in faulty conditions (Figure 5(b)). Given that the broken tooth was in the pinion, which is mounted on the output shaft, the frequency of interest is the rotational frequency of the output shaft $\left(f_{\text {out }}=20.1 \mathrm{~Hz}\right)$.

When the gear is operating with a localized fault, the vibration gathered can be classified as a multicomponent signal, amplitude-modulated (AM) and frequency-modulated (FM). It is not easy to find out which gear is faulty by simply performing the FFT. Therefore, further analysis in the timefrequency domain is required. The ICD algorithm is utilized to analyse the vibration signal coming from a gear in broken tooth fault condition. Firstly, the ICD method is applied to decompose the vibration signal in products. The decomposition process gives four PCs. Secondly, the PCs are enveloped and the frequency spectrum is performed to find the fault frequency. Results shown in Figure 10 are obtained after conducting the envelope spectrum analysis of the four PCs. As seen from Figures 10(a), 10(b), and 10(c) corresponding to the envelope spectrum of $\mathrm{PC} 1(t), \mathrm{PC} 2(t)$, and $\mathrm{PC} 3(t)$, there are obvious spectrum lines of the faulty frequency $\left(f_{\text {out }}=\right.$ $20.1 \mathrm{~Hz})$ and the gear mesh frequency $(\mathrm{GMF}=540 \mathrm{~Hz})$ and sidebands around it spaced a distance equal to the faulty frequency $(499.8 \mathrm{~Hz}, 519.9 \mathrm{~Hz}, 560.1$, and $580.2 \mathrm{~Hz})$. The amplitude of the fault peak is lower than the amplitude of the peak related to the rotating speed. It can be confusing as someone could think that the defective gear is the one at the input of the gearbox when it is the opposite. As shown in Figure 10, the spectrum of the enveloped signal is cleaner with each new iteration of the method but it stills keeping the frequency of interest $\left(f_{\text {out }}\right)$. Figure $10(\mathrm{~d})$ shows the spectrum of the last PC derived from the ICD method. This is the clearest PC spectrum since the number of peaks has been sufficiently reduced and there is a peak which is bigger than the rest. This peak, located at $20.1 \mathrm{~Hz}$, brings to light the source of defect which is a broken tooth at the pinion. In the light of the results, the ICD method simplifies the defect identification process and consequently easing the automation of this type of processes.

Bearings are another important source of failure within gearboxes. Vibrations coming from bearings are AM-FM multicomponent signals which do not show the source of defect clearly. The features of the fault are modulated and its extraction is complicated. Therefore, the ICD method is applied to showcase its fault detection capabilities in other gearbox components. In this case, the aim is to detect an outer race defect in a roller ball bearing. As demodulation is needed, the signal is decomposed and the fault type identification is carried out by applying envelope spectra. Figure 11(a) shows the frequency spectrum of an outer race defect signal before any demodulation is applied. The rotation speed was $20 \mathrm{~Hz}$ at the acquisition moment. As can be seen, the governing frequency is the running speed set up in the VFD $\left(f_{1}=\right.$ $20 \mathrm{~Hz}$ ). The faulty feature can be identified in the spectra in spite of the fact that its amplitude is much lower (BPFO = $60.89 \mathrm{~Hz}$ ). In addition, a clearest indication of the source of defect is needed due to the fact that the BPFO could be confused with the third harmonic of the rotating speed. ICD is applied to this fault signal and the decomposed products are shown in Figures 11(b) and 11(c). After two iterations, the BPFO becomes noticeable being the peak with the highest amplitude of the frequency spectrum (Figure 11(b)). The ICD has demonstrated to be effective identifying outer race defects in bearings. 


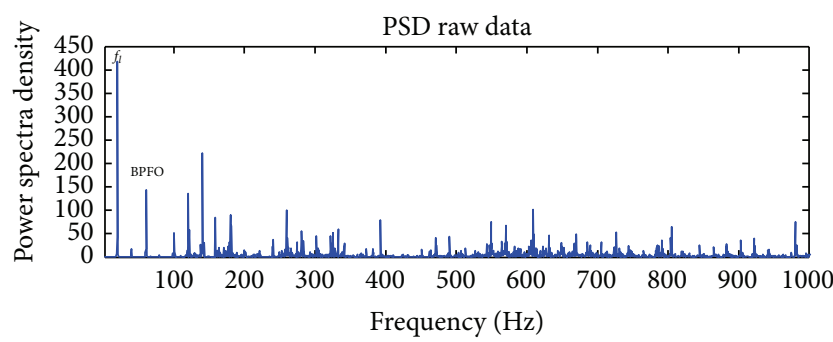

(a)

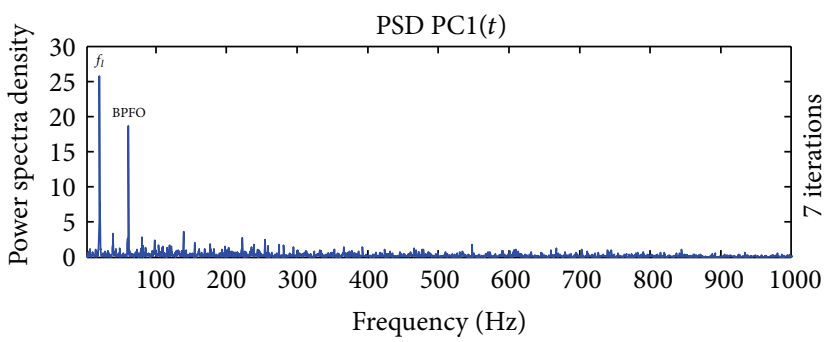

(b)

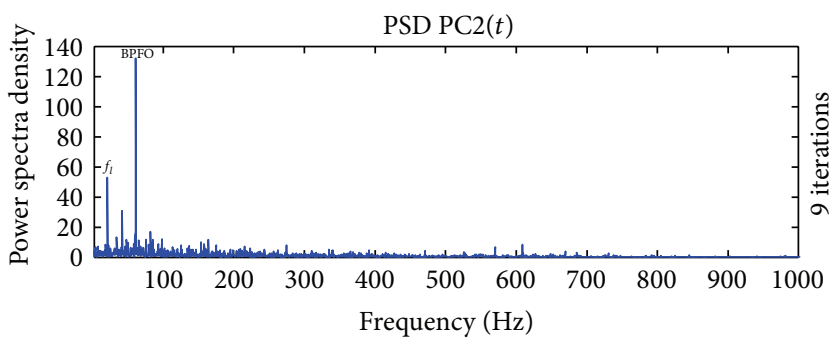

(c)

FIGURE 11: PSD of the raw signal and envelope spectra of the obtained components from ICD (bearing): (a) PSD raw data, (b) PC1(t), and (c) $\operatorname{PC} 2(t)$.

\section{Field Trials on a Vestas V90-3MW Wind Turbine}

Experiments were conducted in a Vestas V90-3MW wind turbine to validate the methodology above explained on field. In this section, the set-up in the wind turbine gearbox and results obtained after applying the algorithm described in Figure 2 are presented. The aim of the experiments is to assess the health of the gearbox and if there is any sign of defect, identify the source.

4.1. Experimental Set-Up and Gearbox Analysis. The wind turbine selected for accomplishing the field trials was a Vestas V90-3MW which consist of a drive train (generator, main shaft, and gearbox), control system, three blades, yaw system, and the tower. Hereafter the wind turbine monitoring setup is described. It consists of a set of three accelerometers, a data acquisition system (DAQ), referred to as CMS which was located in the inside of the nacelle and a data server (CMS server) located in the inside of the nacelle as well. The rotational speed signature (rpm) and power output (kW), which are recorded as an average of the last ten minutes, are supplied by the wind turbine operator.

The CMS utilizes vibration analysis for monitoring the gearbox of the wind turbine, which consists of two planetary gear stages and one helical gear stage, as shown in Figure 12. It is located in the middle of the wind turbine drive. Wind turbine gearboxes are used to increase the rotor speed to a speed suitable for the generation of electricity and operate under varying load conditions. Therefore, there is a low speed shaft (connected to the blades) and high speed shaft (connected to the generator) which are related through the gearbox (ratio 104.5582). Detailed information of this gearbox is provided in Table 4 . The first stage is planetary, in which
TABLE 4: Vestas V90-3MW gear teeth information.

\begin{tabular}{lccc}
\hline \multirow{2}{*}{ Gear stage } & \multicolumn{3}{c}{ Number of gear teeth } \\
& Ring gear/gear & Planet & Sun/pinion \\
\hline Planetary stage I & 87 & 33 & 18 \\
Planetary stage II & 99 & 40 & 18 \\
Helical stage III & 91 & & 33 \\
\hline
\end{tabular}

TABLE 5: Rotational frequencies for each stage.

\begin{tabular}{lccc}
\hline \multirow{2}{*}{ Gear stage } & \multicolumn{3}{c}{ Frequency (orders) } \\
& Planet carrier/gear & Planet & Sun/pinion \\
\hline Planetary stage I & $1 \mathrm{x}$ & $1.59 \mathrm{x}$ & $5.8 \mathrm{x}$ \\
Planetary stage II & $5.8 \mathrm{x}$ & $8.5 \mathrm{x}$ & $37.9 \mathrm{x}$ \\
Helical stage III & $37.9 \mathrm{x}$ & & $104.5 \mathrm{x}$ \\
\hline
\end{tabular}

the planetary carrier (fixed by the ring gear) is the input, Table 4 . The first stage is planetary, in which the planetary carrier (fixed by the ring gear) is the input and the sun gear is the output terminal. The second stage is equal to the first stage. The transmission ratio will not be the same as the number of teeth is different. The third stage consists of a gear which is connected to the output of the previous stage and a pinion. The pinion is at the output of the gearbox and determines the speed of the high speed shaft (HSS). The forcing frequencies to take into account when analysing gearbox data in the frequency domain are the rotational frequencies of the gears and the gear mesh frequency. These values are depicted in Tables 5 and 6, respectively.

For the application of vibration analysis to the wind turbine gearbox, three 3-axis piezoelectric accelerometers (Metra KS943 $100 \mathrm{mV} / \mathrm{g}$ ) with integrated built-in preamplifiers (IEPE standard) were used. Furthermore there is a need 
TABLE 6: Forcing frequencies for each stage.

\begin{tabular}{lc}
\hline Gear mesh frequency (GMF) & Frequency (orders) \\
\hline GMF stage I & $104.91 \mathrm{x}$ \\
GMF stage II & $681.98 \mathrm{x}$ \\
GMF stage III & $3447.76 \mathrm{x}$ \\
\hline
\end{tabular}

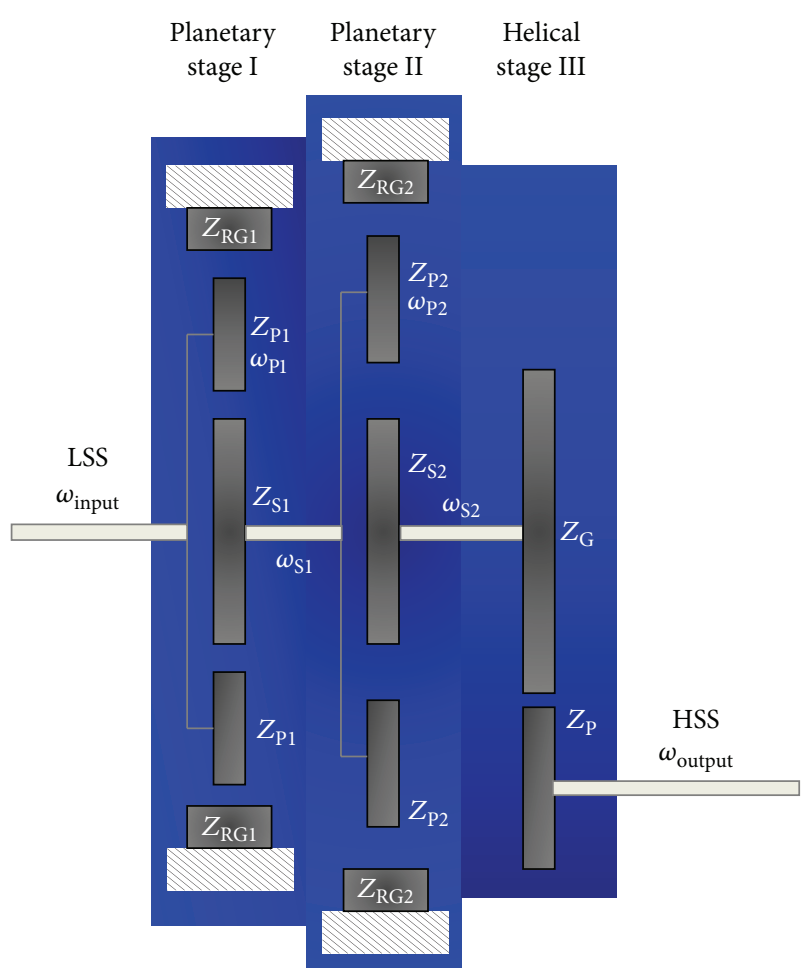

FIGURE 12: Sketch of the Vestas V90-3MW gearbox configuration.

for converters for each acceleration channel and a power supply of $24 \mathrm{~V}$. Because the frequency range used is below $1 \mathrm{kHz}$, the sensors could be magnetically attached to the gearbox surface. Special magnets, which are available as accessories for this type of sensors, were used. The IEPE converters provide the data acquisition card with the voltage output of the 3-axis of each sensor which is proportional to the vibration measured by the transducers. The accelerometers were attached to the gearbox as shown in Figure 13: VIB1, first planetary stage; VIB2, second planetary stage, and VIB3, helical stage. Figure 13(b) shows the position of the sensor with respect to the global axis of the machine.

4.2. Results Analysis. The results from the field trials performed in a Vestas V90-3MW wind turbine between May and October 2015 are presented in Figure 14. A preliminary study based on the power curve for the Vestas V90 and the changes experienced by the features (RMS) extracted over time is presented. Then the baseline and ICD algorithms are applied to the field trials data for the health assessment of the monitored turbine.

The power curve for the Vestas V90-3MW, which shows the wind turbine's power output versus the rotor speed, is shown in Figure 14. This is a performance indicator which can be used as first preventive maintenance indication that something is wrong. When a failure in the turbine occurs, power deviates from the normal power curve. In Figure 14, May and October power curves are superposed and no deviations are noticed. Therefore, this indicator designates no presence of malfunction at first sight.

Figure 15 depicts the clustering of the data features using a binning process based on the rotor speed, measured at the low speed shaft (16 rpm maximum). Figure 15 shows the number of files stored in each bin. Considering rotor speed as the binning parameter, the number of files increases from bin 18 to bin 30 which means that the rotor speed varied mostly between $10 \mathrm{rpm}$ and $16 \mathrm{rpm}$ during the months the system was installed in the wind turbine. The shape of the distribution makes sense bearing in mind that turbines operate at high speed for power generation purposes.

To get a better idea of how the data looks like and have a second performance indicator before the algorithm is applied, the RMS of the vibrations collected within the months of May and October are plotted in Figure 16. It gives a good overview of how the RMS changes versus time per bin. The RMS does not show large variations with time. However there are a couple of peaks which are of interest. These peaks are located in the first two bins and in the last one. The peaks recorded at low rotor speeds occurred at mid-August whereas the one captured at higher speeds happened at the beginning of September and its RMS value is around $8 \mathrm{~m} / \mathrm{s}^{2}$. Further research revealed that those files which have higher RMS values were corrupted.

Following on, the baseline generation process and the health assessment based on its limits is presented. During the six months the field trials were taking place, the operator did not carry out any maintenance actions so it is assumed that the machinery is in a healthy status and the data collected is very valuable for the generation of a baseline. This baseline will mark the limits of normal operation conditions for this particular turbine. The baseline will be a useful tool for wind turbine operators so the maintenance actions are only carried out when deviations from the target value are noticed and verified as defect initiation, worsening or malfunction of the gearbox.

The convergence criterion is applied to all the bins. The results are depicted just for bin 30 though. Figure 17 shows how the EMA gets lower with every RMS value added to bin 30. The EMA in this bin starts dropping very fast from the beginning and converge after some measurement due to the fact that the EMA is close to $0 \%$. The stopping criterion stipulates the minimum number of files as 34 (dotted line in Figure 17).

Figure 18 depicts the baseline obtained after calculating the minimum number of data necessary to establish the alarm and warning limits reliably in each bin. This baseline is unique for this turbine and is suitable for monitoring at low or high rotor speeds, covering the wind turbine through all its operational range. The number of files utilized for calculating the limits varies depending on the result obtained after evaluating the convergence criteria (see values in Table 7). The results 


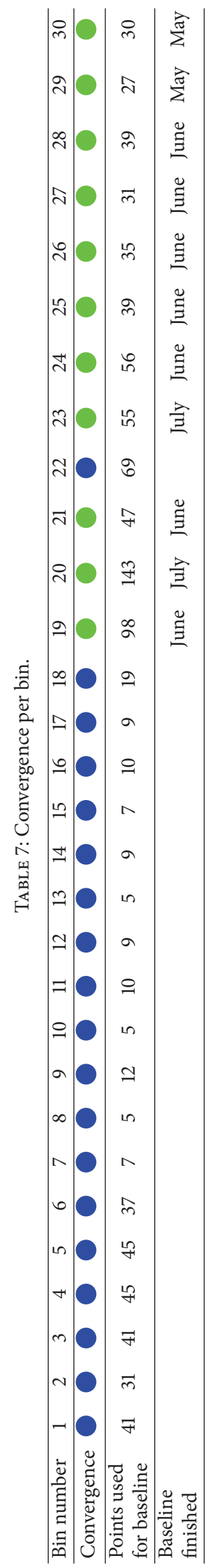




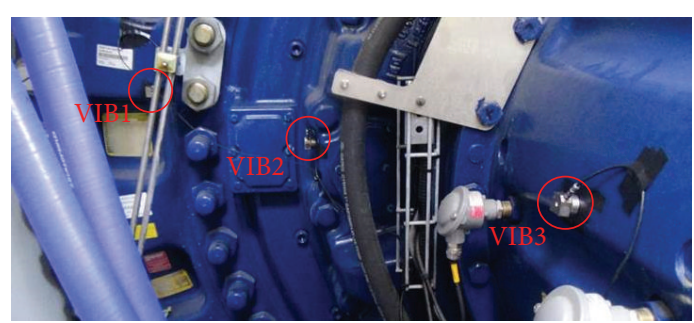

(a)

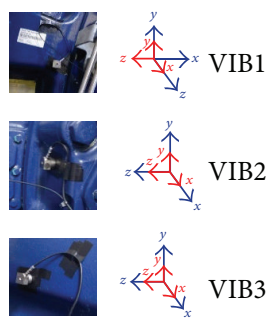

(b)

FiguRE 13: Sensors attachment on the gearbox: (a) set-up and (b) global (red) and local (blue) axis.

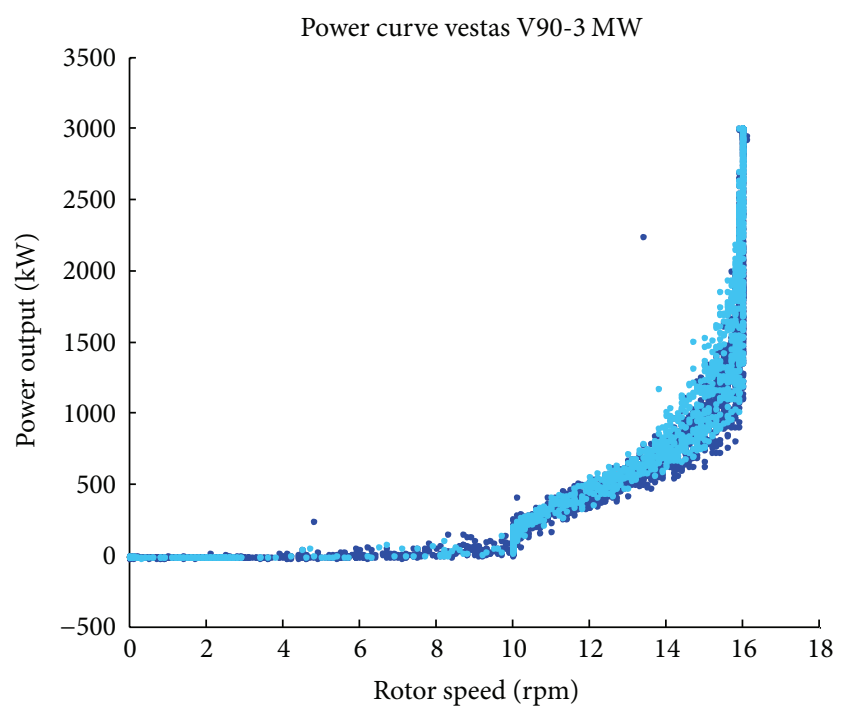

- May 2015

- October 2015

FIGURE 14: Scatter plot with power output as function of the rotor speed.

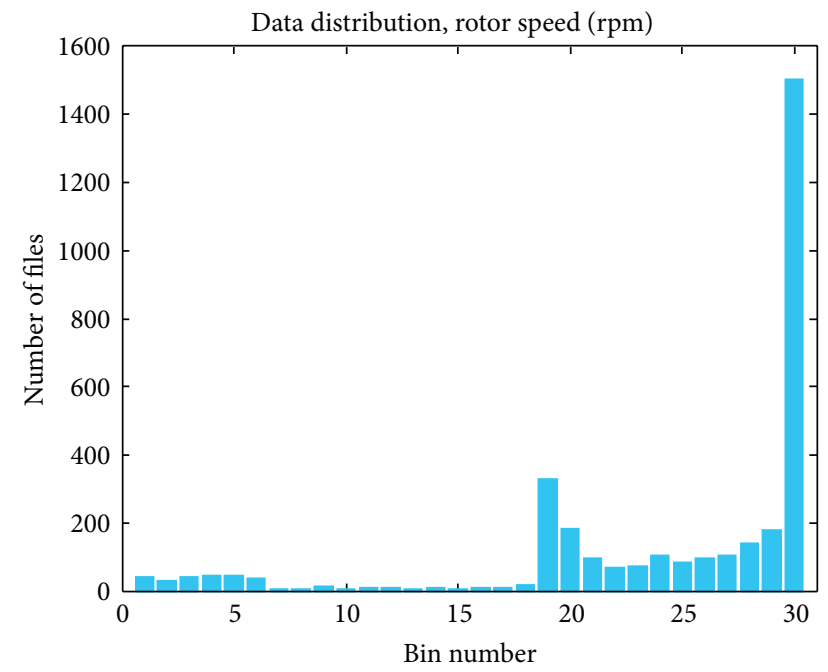

FIGURE 15: Distribution of the wind turbine data gathered using 30 bins.

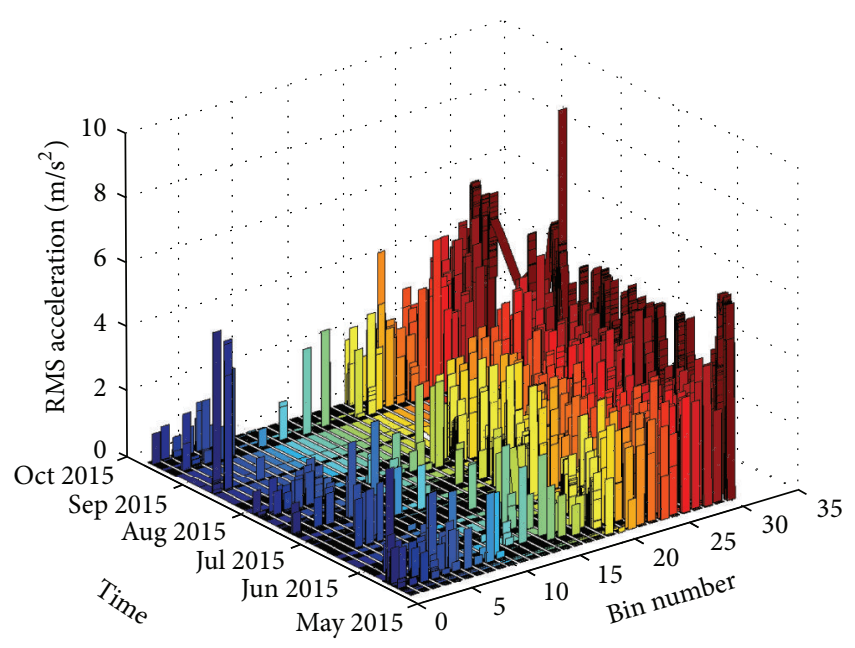

FIGURE 16: Variation on the RMS value of the acceleration per bin.

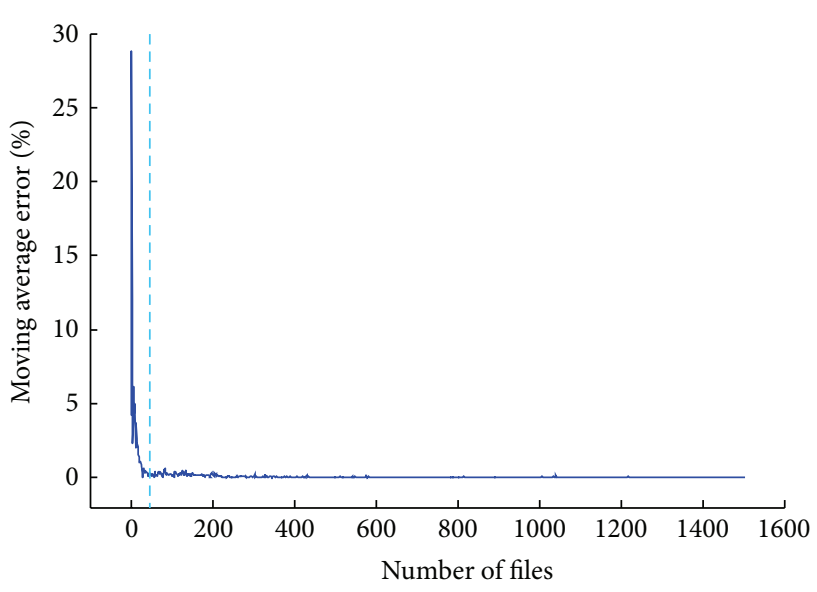

FIGURE 17: Convergence in bin 30.

point out that convergence was not reached in all the bins. According to the results, the fact of not reaching the convergence criterion in some bins is associated directly with the number of data clustered in them. As commented previously in the paper, the number of events recorded at low speed is very low. The method does not converge in the low speed bins, where there is not convergence of the method. It can be 


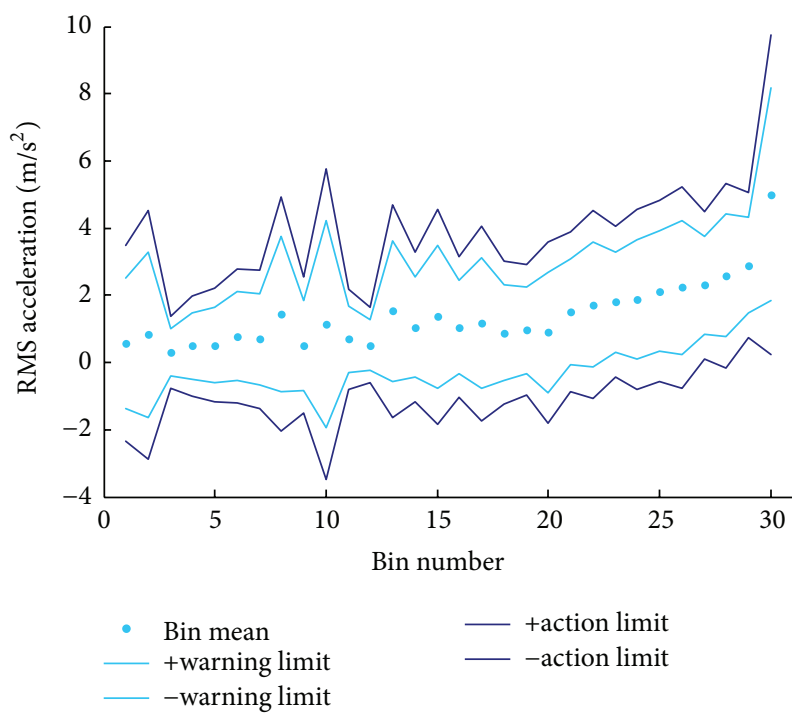

FIGURE 18: Baseline and targeted mean for a Vestas V90-3MW wind turbine.

noticed that the number of data clustered in them is less than 70 files. It does not mean that provisional values cannot be given to the limits. It means that more data is required in order to average the current value more and set the limits in a more confident way. At high rotor speeds the baseline has been properly defined, reaching the convergence in all the bins apart from bin 22 (which only contains 69 files). Most of the bins converged in June although some of them did it earlier (May) and others a bit later (July). Therefore, it can be concluded that a period of three months was necessary to define the baseline complying with the convergence criteria.

Figure 18 depicts the warning and action limits which define zones A, B, and C along with the targeted mean of the RMS values of the acceleration signals stored in each bin.

After defining the baseline, the machine goes into the monitoring stage. The data gathered after satisfying the convergence criterion is plotted along with the limits in Figure 19 to evaluate their deviation from the targeted mean. In this figure the limits still have the same values but there are two sets of data presented in different colours. The blue colour points out that convergence was not reached in those bins. On the other hand the green colour indicates the convergence within those bins and the points represent the data gathered after the baseline was defined. The results depicted in Figure 19 are very promising, specially bearing in mind that this data is totally independent of the data previously used for the limits establishment. The new data consist of more than 2000 RMS values which mostly fall within the limits. There are some outliers though. The percentage of outliers between the warning and alarm limits has been estimated: $0 \%$ in bin 20,2\% in bin $21,1.6 \%$ in bin 26 , and $2.5 \%$ in bin 30 . Since it was chosen to add 2 times the standard deviation to the mean as a warning strategy a $5 \%$ of the data within each bin can fall outside the limits. The percentages are good as they are lower than a $5 \%$. There are points above the alarm limits as well. For instance, that happens in bins 19,29, and 30. The percentage of outliers

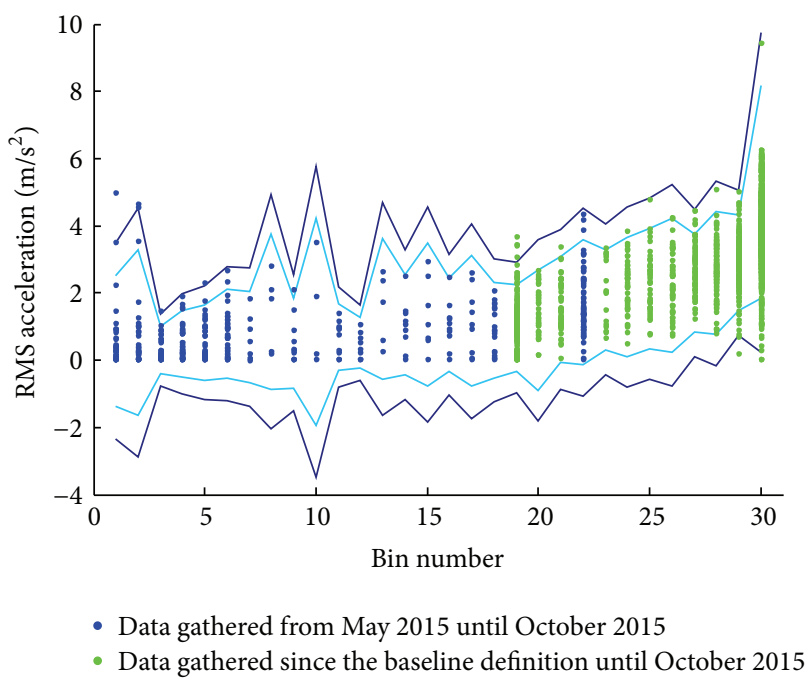

FIGURE 19: Monitoring using a 3-month established baseline.

in those bins is $0.4 \%, 0.3 \%$, and $0.12 \%$. Since it was chosen to add 3 times the standard deviation to the mean as a warning strategy a $0.2 \%$ of the data within each bin can fall outside the limits. The resulting percentage is good for bin 30 as it is lower than $0.2 \%$. For the other two bins the percentages are acceptable as they are slightly bigger than $0.2 \%$. Therefore the results shown in Figures 18 and 19 are a good tool for describing the acceptable levels of vibration of the wind turbine gearbox regarding the rotor speed of the wind turbine.

Outliers need to be further studied to find out the root cause of the deviations. One outlier per bin was analysed using the ICD method and the forcing frequencies were calculated according to the gearbox information provided in Table 6. The demodulation of the signal was carried out in six iterations which are shown in Figure 20. After $\mathrm{PCl}(t)$ was obtained, the envelope spectrum of the signal shows the gear mesh frequency at the 3rd stage. This is the only peak that matches with the forcing frequencies theoretically calculated. In the following stages of the demodulation, the peak disappears which means that it was not a fault feature modulated by other frequencies. PC2 $(t), \mathrm{PC} 3(t), \mathrm{PC} 4(t), \mathrm{PC} 5(t)$, and PC6 $(t)$ do not show explicit spectra lines of the fault frequencies of the gears. Therefore, the ICD does not show indication of gear defects within the gearbox.

\section{Conclusions}

This paper presents a novel approach for health condition monitoring and fault diagnosis in wind turbine gearboxes. The paper proposes baseline and ICD-based early fault diagnosis methodologies which are tested on laboratory and wind turbine vibration signals.

A baseline which represents the normal operation boundaries of the test rig and a Vestas V90-3MW have been produced. It is important to state that the resultant baseline from the laboratory trials has been validated and it has been accomplished with two sets of independent data (one healthy and another one from a gearbox with a broken tooth). 


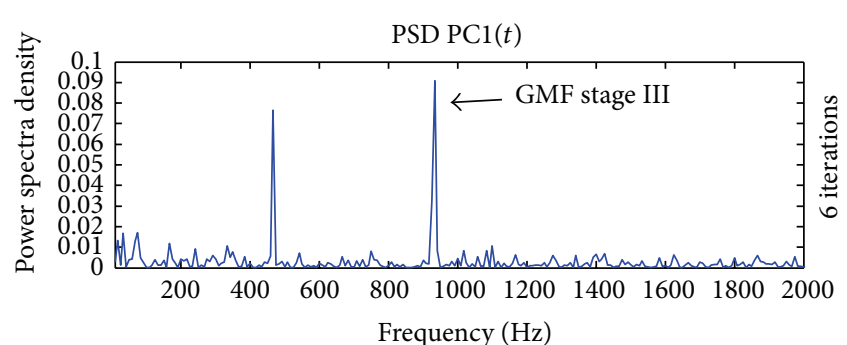

(a)

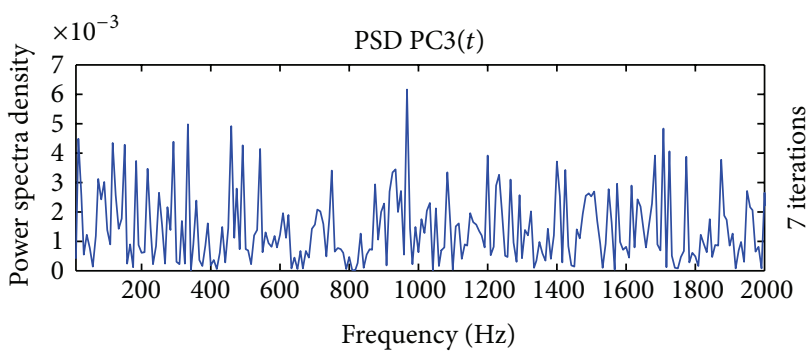

(c)

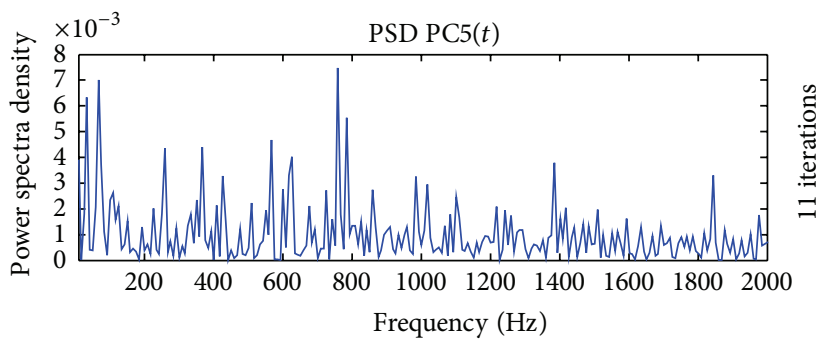

(e)

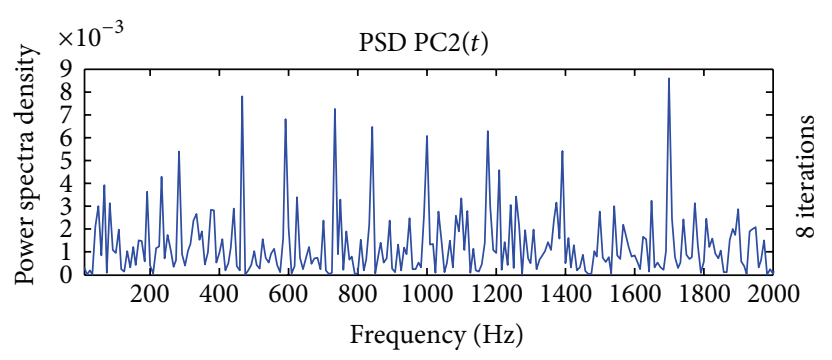

(b)

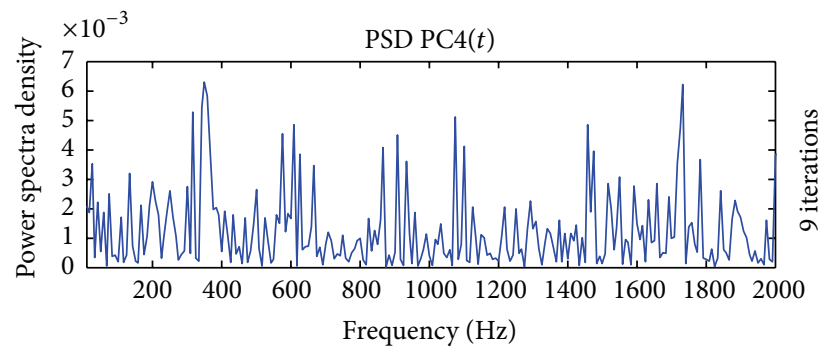

(d)

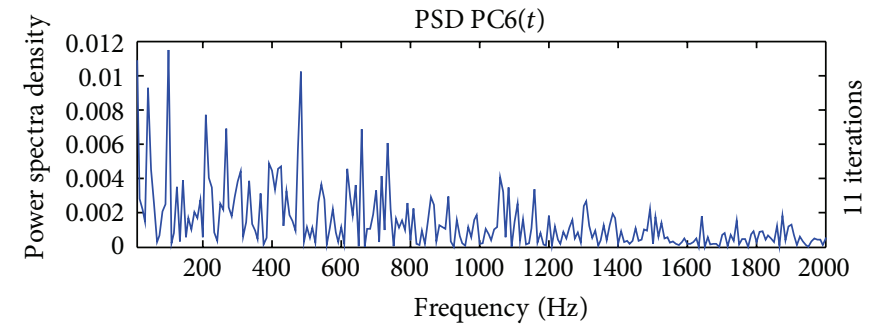

(f)

Figure 20: PSD of the envelope spectra of the obtained components from ICD (wind turbine data): (a) PC1(t), (b) PC2 (t), (c) PC3(t), (d) PC4 $(t)$, (e) PC5 $(t)$, and (f) PC6 $(t)$.

Deviations from the targeted mean appear when the faulty set of data is utilized. The application of the baseline algorithm to the Vestas V90-3MW data establishes the range within the machine is running safely. Some outliers were identified at high running speeds, which is not very worrying as the outlier rate is lower or close to the value established by the probability factor. The validation expounds this methodology as a good practice for identifying those deviations which worries manufactures and wind turbine operators nowadays.

The process carried out for classifying the outliers at the laboratory demonstrates that the combination between the ICD method and the envelope spectrum analysis is superbly efficient for broken tooth and outer race fault diagnosis. The ICD method is experimentally demonstrated to be able to extract the early fault signature effectively. The algorithm was used to process the wind turbine outliers as well. However, the demodulated signal does not show any defect feature. This result, along with the output coming from the power curve indicator and the information provided by the operator regarding the health of the machinery, exhibits the lack of defect in the gears within the gearbox subsystem. Then, the outliers found at high speeds are considered false alarms.
The application of the ICD method simplifies the defect identification process due to the following two factors: the number of peaks in the spectrum is lower and the source of defect is shown as the peak with the biggest amplitude. Therefore, the ICD method eases the automation of the defect detection processes carried out by CMS which allows looking for the source of defect in real time.

\section{Competing Interests}

The authors declare that they have no competing interests.

\section{References}

[1] S.-W. Choi, K. M. Farinholt, S. G. Taylor, A. Light-Marquez, and G. Park, "Damage identification of wind turbine blades using piezoelectric transducers," Shock and Vibration, vol. 2014, Article ID 430854, 9 pages, 2014.

[2] S. Sheng and P. Veers, Wind Turbine Drive Train Condition Monitoring-An Overview, National Renewable Energy Laboratory, Golden, Colo, USA, 2011.

[3] Y. Gui, Q. K. Han, Z. Li, and F. L. Chu, "Detection and localization of tooth breakage fault on wind turbine planetary gear 
system considering gear manufacturing errors," Shock and Vibration, vol. 2014, Article ID 692347, 13 pages, 2014.

[4] R. Moesgaard, H. Chandler, P. Barons, and G. Bakema, Wind Energy-The Facts, The Economics of Wind Power, Earthscan, 2009.

[5] S. Sheng, "Investigation of various wind turbine drivetrain condition monitoring techniques," in Proceedings of the Wind Turbine Reliability Workshop, Albuquerque, NM, USA, August 2011.

[6] M. Strączkiewicz and T. Barszcz, "Application of artificial neural network for damage detection in planetary gearbox of wind turbine," Shock and Vibration, vol. 2016, Article ID 4086324, 12 pages, 2016.

[7] Y. Feng, Y. Qiu, C. J. Crabtree, H. Long, and P. J. Tavner, "Monitoring wind turbine gearboxes," Wind Energy, vol. 16, no. 5, pp. 728-740, 2013.

[8] S. Sheng, Wind Turbine Drivetrain Condition Monitoring, Power Point Presentation, NREL/NWTC, New York, NY, USA, 2011.

[9] F. P. García Márquez, A. M. Tobias, J. M. Pinar Pérez, and M. Papaelias, "Condition monitoring of wind turbines: techniques and methods," Renewable Energy, vol. 46, pp. 169-178, 2012.

[10] F. P. Garcia, J. M. Pinar, A. Pliego, and M. Papaelias, "Identification of critical components of wind turbines using FTA over the time," Renewable Energy, vol. 46, pp. 169-178, 2012.

[11] Z. Tian, T. Jin, B. Wu, and F. Ding, "Condition based maintenance optimization for wind power generation systems under continuous monitoring," Renewable Energy, vol. 36, no. 5, pp. 1502-1509, 2011.

[12] C. C. Ciang, J.-R. Lee, and H.-J. Bang, "Structural health monitoring for a wind turbine system: a review of damage detection methods," Measurement Science and Technology, vol. 19, no. 12, Article ID 122001, 20 pages, 2008.

[13] A. Kusiak and W. Li, "The prediction and diagnosis of wind turbine faults," Renewable Energy, vol. 36, no. 1, pp. 16-23, 2011.

[14] D. Yang, H. Li, Y. Hu, J. Zhao, H. Xiao, and Y. Lan, "Vibration condition monitoring system for wind turbine bearings based on noise suppression with multi-point data fusion," Renewable Energy, vol. 92, pp. 104-116, 2016.

[15] B. N. Madsen, Condition monitoring of wind turbines by electric signature analysis [M.S. thesis], Technical University of Denemark, Copenhagen, Denmark, 2011.

[16] P. Tchakoua, R. Wamkeue, M. Ouhrouche, F. Slaoui-Hasnaoui, T. A. Tameghe, and G. Ekemb, "Wind turbine condition monitoring: state-of-the-art review, new trends, and future challenges," Energies, vol. 7, no. 4, pp. 2595-2630, 2014.

[17] Z. Hameed, Y. S. Hong, Y. M. Cho, S. H. Ahn, and C. K. Song, "Condition monitoring and fault detection of wind turbines and related algorithms: a review," Renewable and Sustainable Energy Reviews, vol. 13, no. 1, pp. 1-39, 2009.

[18] Noordzee Wind, "Operation Report 2009. Document No. OWEZ_R_000_20101112,” November 2010, http://www.noordzeewind.nl/wpcontent/uploads/2012/02/OWEZ_R_000_20101112_ Operations_2009.pdf.

[19] C. J. Crabtree, D. Zappala, and P. J. Tavner, "Survey of commercially available condition monitoring systems for wind turbines," Tech. Rep., Durham University, 2014.

[20] A. May, D. McMillan, and S. Thöns, "Economic analysis of condition monitoring systems for offshore wind turbine subsystems," IET Renewable Power Generation, vol. 9, no. 8, pp. 900-907, 2015.
[21] S. Soua, P. Van Lieshout, A. Perera, T.-H. Gan, and B. Bridge, "Determination of the combined vibrational and acoustic emission signature of a wind turbine gearbox and generator shaft in service as a pre-requisite for effective condition monitoring," Renewable Energy, vol. 51, pp. 175-181, 2013.

[22] T. Toutountzakis and D. Mba, "Observations of acoustic emission activity during gear defect diagnosis," NDT \& E International, vol. 36, no. 7, pp. 471-477, 2003.

[23] C. Molina, "Contributions to the analysis of vibration and acoustic emissions for the condition monitoring of epicyclic gearboxes," 2010.

[24] C. K. Tan, P. Irving, and D. Mba, "A comparative experimental study on the diagnostic and prognostic capabilities of acoustics emission, vibration and spectrometric oil analysis for spur gears," Mechanical Systems and Signal Processing, vol. 21, no. 1, pp. 208-233, 2007.

[25] R. Ahmad and S. Kamaruddin, "An overview of time-based and condition-based maintenance in industrial application," Computers and Industrial Engineering, vol. 63, no. 1, pp. 135-149, 2012.

[26] R. B. Randall, Vibration-Based Condition Monitoring: Industrial, Aerospace and Automotive Applications, John Wiley \& Sons, New York, NY, USA, 2011.

[27] P. Vecer, M. Kreidl, and R. Smid, "Condition indicators for gearbox condition monitoring systems," Acta Polytechnica, vol. 45, no. 6, pp. 3-17, 2005.

[28] K. Fischer, Maintenance Management of Wind Power Systems by Means of Reliability-Centred Maintenance and Condition Monitoring Systems, Chalmers University of Technology, Gothenburg, Sweden, 2012.

[29] S. Sheng, "Wind turbine gearbox condition monitoring round robin study-vibration analysis," Tech. Rep., National Renewable Energy Laboratory, Denver, Colo, USA, 2012.

[30] D. F. Shi, L. S. Qu, and N. N. Gindy, "General interpolated fast fourier transform: a new tool for diagnosing large rotating machinery," Journal of Vibration and Acoustics, vol. 127, no. 4, pp. 351-361, 2005.

[31] M. Inalpolat and A. Kahraman, "A dynamic model to predict modulation sidebands of a planetary gear set having manufacturing errors," Journal of Sound and Vibration, vol. 329, no. 4, pp. 371-393, 2010.

[32] M. Inalpolat and A. Kahraman, "A theoretical and experimental investigation of modulation sidebands of planetary gear sets," Journal of Sound and Vibration, vol. 323, no. 3-5, pp. 677-696, 2009.

[33] M. E. Badaoui, F. Guillet, and J. Danière, "New applications of the real cepstrum to gear signals, including definition of a robust fault indicator," Mechanical Systems and Signal Processing, vol. 18, no. 5, pp. 1031-1046, 2004.

[34] Y. Itoh, T. Imazu, H. Nakamura, and T. Yamazaki, Vibration Analysis Based on Time-Frequency Analysis with a Digital Filter: Application to Nonlinear System Identification, Inter.noise, Melbourne, Australia, 2014.

[35] R. Bajric, N. Zuber, G. A. Skrimpas, and N. Mijatovic, "Feature extraction using discrete wavelet transform for gear fault diagnosis of wind turbine gearbox," Shock and Vibration, vol. 2016, Article ID 6748469, 10 pages, 2016.

[36] L. Cohen, Time Frequency Analysis, vol. 778, Prentice Hall PTR, Englewood Cliffs, NJ, USA, 1995. 
[37] W. J. Staszewski, K. Worden, and G. R. Tomlinson, “Timefrequency analysis in gearbox fault detection using the WignerVille distribution and pattern recognition," Mechanical Systems and Signal Processing, vol. 11, no. 5, pp. 673-692, 1997.

[38] M. Timusk, M. Lipsett, and C. K. Mechefske, "Fault detection using transient machine signals," Mechanical Systems and Signal Processing, vol. 22, no. 7, pp. 1724-1749, 2008.

[39] W. J. Staszewski and G. R. Tomlinson, "Application of the wavelet transform to fault detection in a spur gear," Mechanical Systems and Signal Processing, vol. 8, no. 3, pp. 289-307, 1994.

[40] H.-J. Kou, H.-Q. Yuan, and X.-Y. Zhao, "Application of wavelet de-noising in fault diagnosis of wind turbine gearboxes," Advanced Materials Research, vol. 562-564, pp. 1091-1094, 2012.

[41] F.-C. Zhou, "Research on online monitoring of gear fault of wind power gearbox based on undecimated wavelet transformation," Advanced Materials Research, vol. 383-390, pp. 49284931, 2012.

[42] Y. Lu, J. Tang, and H. Luo, "Wind turbine gearbox fault detection using multiple sensors with features level data fusion," Journal of Engineering for Gas Turbines and Power, vol. 134, no. 4, Article ID 042501, 8 pages, 2012.

[43] S. Yang, W. Li, and C. Wang, "The intelligent fault diagnosis of wind turbine gearbox based on artificial neural network," in Proceedings of the International Conference on Condition Monitoring and Diagnosis (CMD '08), pp. 1327-1330, Beijing, China, April 2008.

[44] I. Antoniadou, G. Manson, N. Dervilis, T. Barszcz, W. Staszewski, and K. Worden, "Condition monitoring of a wind turbine gearbox using the empirical mode decomposition method and outlier analysis," in Proceedings of the 6th European Workshop on Structural Health Monitoring (EWSHM '12), pp. 1316-1323, July 2012.

[45] W. Yang, R. Court, P. J. Tavner, and C. J. Crabtree, "Bivariate empirical mode decomposition and its contribution to wind turbine condition monitoring," Journal of Sound and Vibration, vol. 330, no. 15, pp. 3766-3782, 2011.

[46] Y. Kopsinis and S. McLaughlin, "Investigation and performance enhancement of the empirical mode decomposition method based on a heuristic search optimization approach," IEEE Transactions on Signal Processing, vol. 56, no. 1, pp. 1-13, 2008.

[47] G. G. Pegram, M. C. Peel, and T. A. McMahon, "Empirical mode decomposition using rational splines: an application to rainfall time series," Proceedings of the Royal Society of London, Series A: Mathematical, Physical and Engineering Sciences, vol. 464, no. 2094, pp. 1483-1501, 2008.

[48] Y. Wang, Z. He, and Y. Zi, "A comparative study on the local mean decomposition and empirical mode decomposition and their applications to rotating machinery health diagnosis," Journal of Vibration and Acoustics, vol. 132, no. 2, Article ID 021010, 2010.

[49] M. G. Frei and I. Osorio, "Intrinsic time-scale decomposition: time-frequency-energy analysis and real-time filtering of nonstationary signals," Proceedings of the Royal Society of London A, vol. 463, no. 2078, pp. 321-342, 2007.

[50] G. T. Zheng and P. D. McFadden, "A time-frequency distribution for analysis of signals with transient components and its application to vibration analysis," Journal of Vibration and Acoustics, vol. 121, no. 3, pp. 328-333, 1999.

[51] D. E. Newland, "Ridge and phase identification in the frequency analysis of transient signals by harmonic wavelets," Journal of Vibration and Acoustics, vol. 121, no. 2, pp. 149-155, 1999.
[52] W.-X. Yang and P. W. Tse, "An advanced strategy for detecting impulses in mechanical signals," Journal of Vibration and Acoustics, vol. 127, no. 3, pp. 280-284, 2005.

[53] Y. Li, M. Xu, Y. Wei, and W. Huang, "Rotating machine fault diagnosis based on intrinsic characteristic-scale decomposition," Mechanism and Machine Theory, vol. 94, pp. 9-27, 2015.

[54] R. O. Duda, P. E. Hart, and D. G. Stork, Pattern Classification, John Wiley \& Sons, New York, NY, USA, 2012.

[55] C. R. Farrar and K. Worden, Structural Health Monitoring: A Machine Learning Perspective, John Wiley \& Sons, New York, NY, USA, 2012.

[56] A. Jessop, statNotes: Some Statistics for Management Problems, U. Durham University, World Scientific, 2016.

[57] A. Grous, Applied Quality Control: Fracture Mechanics, vol. 3, John Wiley \& Sons, New York, NY, USA, 2013. 


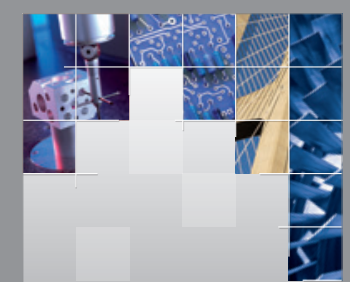

\section{Enfincering}
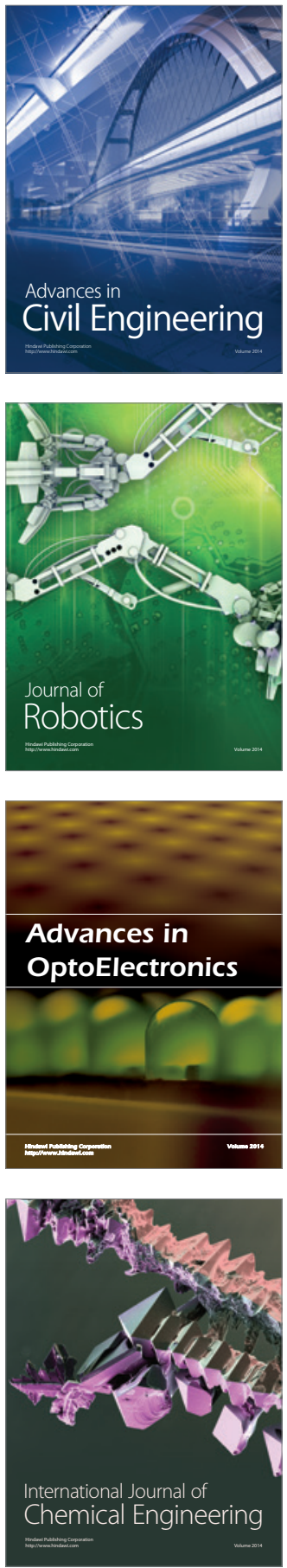

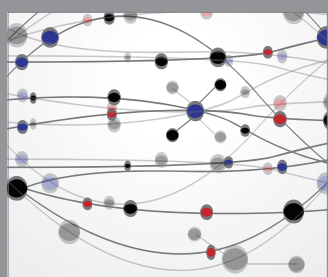

The Scientific World Journal

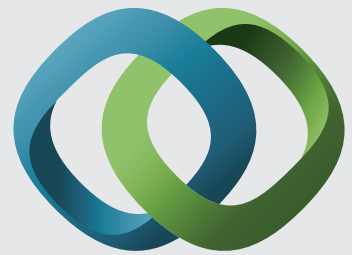

\section{Hindawi}

Submit your manuscripts at

http://www.hindawi.com
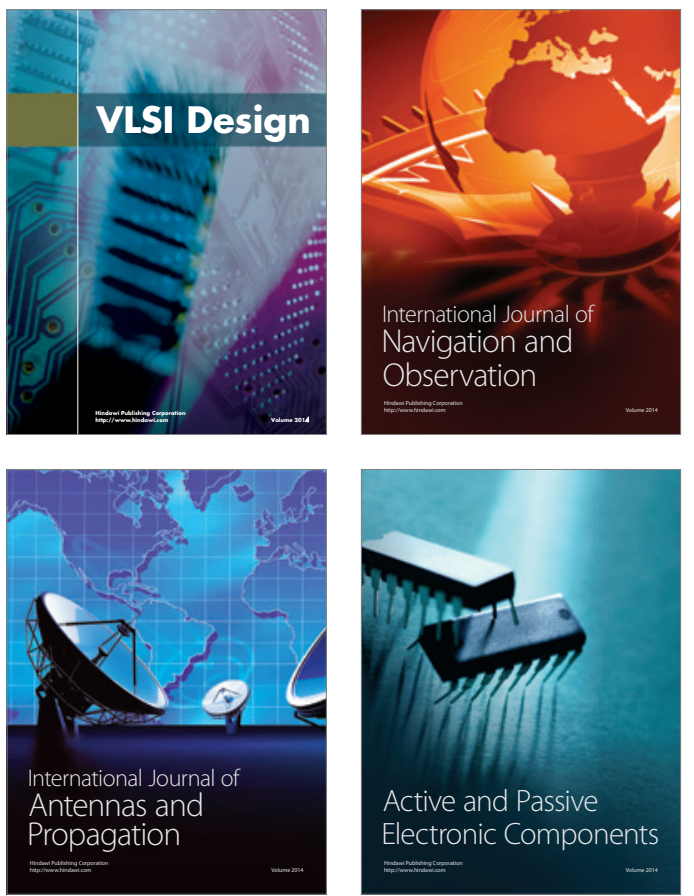
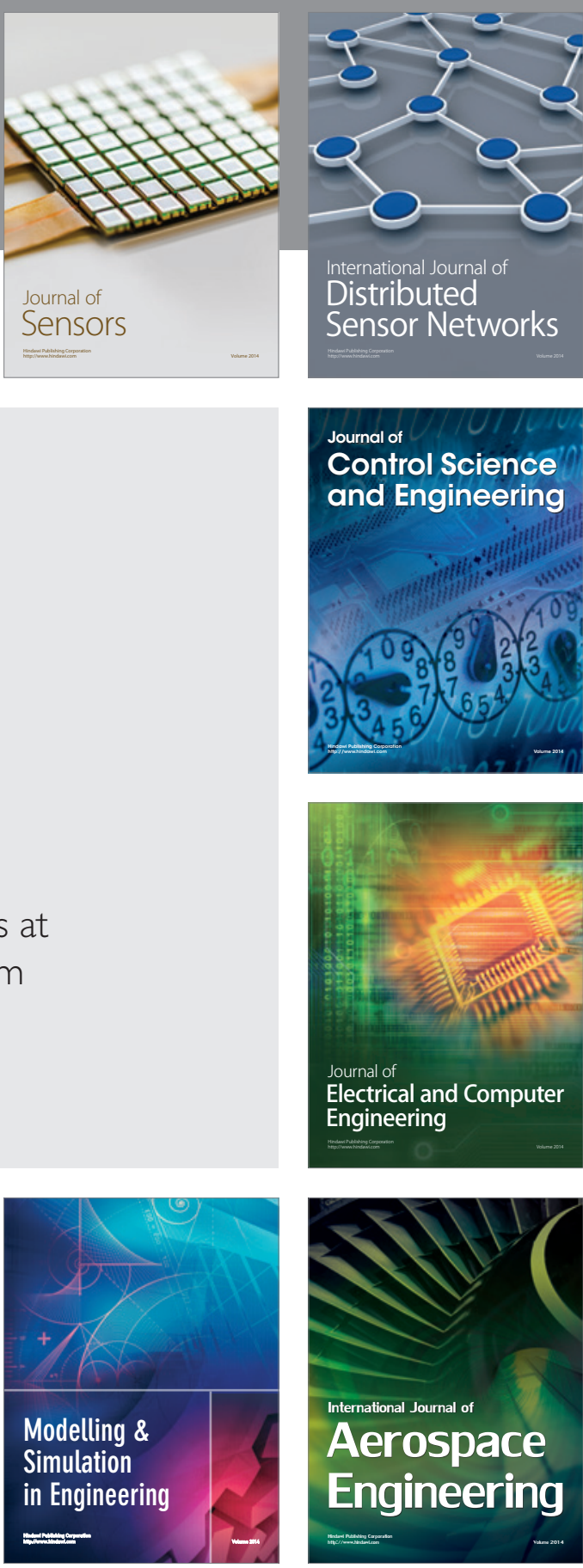

International Journal of

Distributed

Sensor Networks

Journal of

Control Science

and Engineering
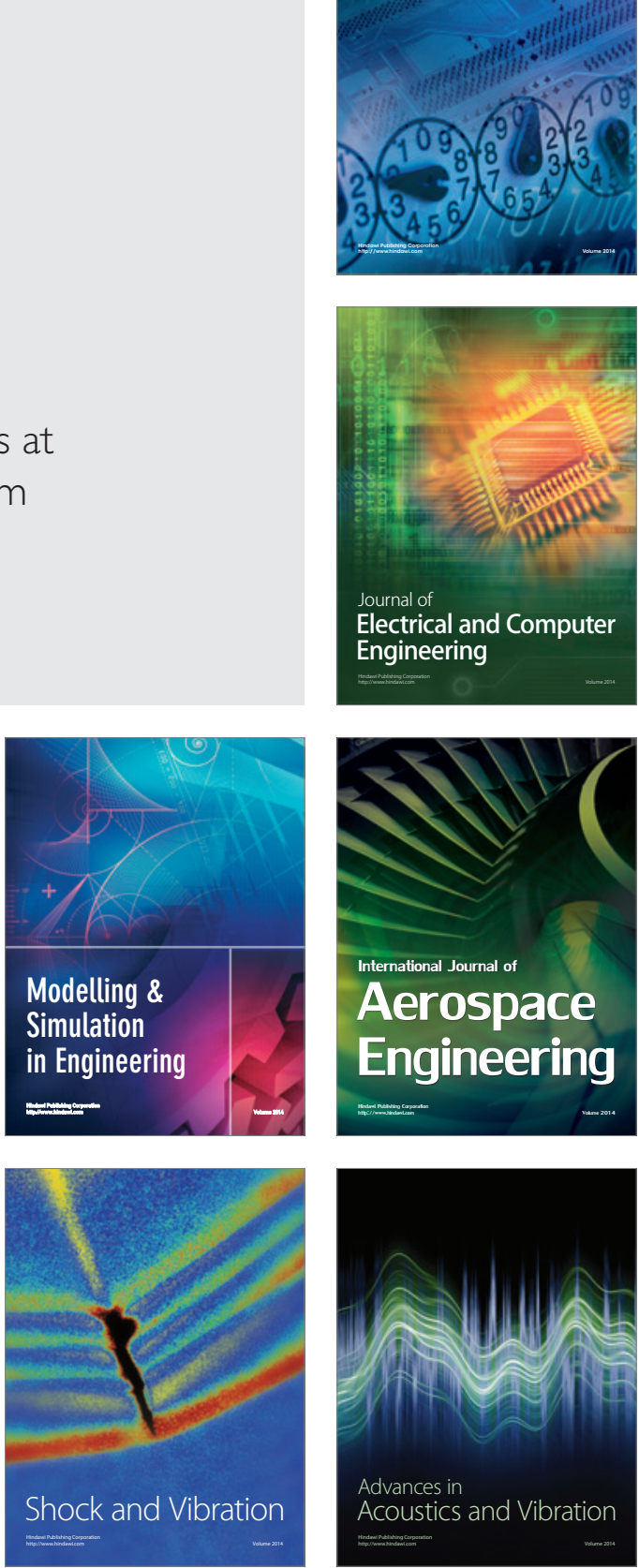